\title{
Dynamic and Static Change of Grain Size and Texture of Copper during Friction Stir Welding
}

$$
\operatorname{Nan} \mathrm{Xu}^{\mathrm{a}, \mathrm{b}, *}, \text { Rintaro Ueji }^{\mathrm{a}} \text { and Hidetoshi Fujii }{ }^{\mathrm{a}}
$$

${ }^{a}$ Joining and Welding Research Institute, Osaka University, 11-1 Mihogaoka, Ibaraki, Osaka 567-0047, Japan

${ }^{b}$ College of Mechanical and Electrical Engineering, Hohai University, Changzhou, 213022, PR China

\begin{abstract}
To comprehensively understand the microstructural evolution during friction stir welding (FSW), the plastic deformation stage and the post-annealing stage of the FSW were separated by a stop action technique associated with liquid $\mathrm{CO}_{2}$ cooling and a subsequent annealing treatment. During the plastic deformation stage, the initial large grains in the base metal were subdivided with the increasing strain and temperature, and the stir zone showed ultrafined grains with a large quantity of low angle boundaries and a symmetrical simple shear texture. During the subsequent annealing stage, static recrystallization occurred, which led to the selected grain growth, and disappearance of dislocations, that produced the simple shear texture change. The stir zone showed a recrystallized-like structure in appearance caused by the static continuous and discontinuous recrystallization. The static restoration caused by the post-annealing effect can significantly affect the microstructure, which is produced by the plastic deformation, and it should not be ignored when discussing the microstructure evolution of the FSW.
\end{abstract}

Keywords: Friction stir welding; stop action technique; rapid cooling; post-annealing effect; microstructure; texture

\footnotetext{
${ }^{*}$ Corresponding author: Tel./fax: +81 066879 8663; E-mail: xu@jwri.osaka-u.ac.jp; xunan20032389@126.com (Nan Xu). 


\section{Introduction}

Friction stir welding (FSW), which is a solid-state joining technology, was invented by Thomas et al. (1991) at The Welding Institute (TWI) of the United Kingdom as a first attempt to join aluminum alloys. FSW provides a superior weldability so that the extension of its application has been strongly desired for more than twenty years. Mishra and Ma (2005) clarified that one of the most significant characteristics of the FSW joint is the grain refinement by recrystallization. Further optimization of the recrystallization requires information about the plastic deformation and the accompanied thermo-assisted change in the microstructure during the FSW process. Humphreys and Hatherly (2004) estimated that the best way to make a good link to the recrystallization should be a crystallographic texture analysis with careful observations of the grains. Both textural and microstructural analyses of the FSW joint with the FCC structure, such as aluminum alloys, copper alloys and austenite stainless steels, have been examined by many researchers, and the obtained main results are summarized in Table 1. The materials undergoes dynamic recrystallization due to the intense deformation and heating by the friction stirring. A grain-refined structure with a non-uniform dislocation density and an obvious shear texture was produced in the stir zone (SZ). The orientation of the shear texture usually depends on the stacking fault energy of the FCC materials. Sato et al. (2005) found a mixture of both static and dynamic recrystallizations based on their examination of the post-annealing phenomena in an austenitic stainless steel. They reported fiber textures, which have never been reported, although they can be explained by a simple shear deformation. This is due to the regions of high dislocation density undergoing static recrystallization for subsequent heating of the tool shoulder. The statically-recrystallized grains exhibit a different orientation from the dominant texture components. However, they did not use a rapid cooling device so that their study is somehow difficult to focus on the effect of plastic deformation. These studies mentioned detailed recrystallization behaviors, but there are no unified opinions. Almost all of these papers did not discuss the grain size distributions linking 
with the grain boundary characteristics. The grain size distribution is a key feature to clarify the recrystallization behavior, especially whether it is continuous or discontinuous.

Prangnell et al. (2005) reported the microstructural and textural evolutions in aluminum alloy joints obtained by a stop-action method with water cooling. Their studies clarified that the texture of $\{112\}$ and $\langle 110\rangle$ are parallel to the columnar surface and the horizontal tangent of the probe, respectively, and the additional observation of the grain structure in the top view provided an important conclusion that these textures are due to simple shear deformation in which the shear plane and the shear direction are parallel to the columnar surface and the horizontal tangent, respectively. These studies included no direct examination of the thermal change in the microstructures.

Although previous studies clarified the importance of both the simple shear deformation and the characteristic recrystallization, their materials were different from each other, which prohibits a simple comparison among their studies, thus it is impossible to separately consider the role of plastic deformation and that of the thermal assisted microstructure change. This study was conducted using the rapid cooling FSW (RC-FSW) and its post-welded heat treatment of copper with the aim to separately clarify the plastic deformation and the thermal change in the microstructure during the FSW.

\section{Experimental procedure}

Two-mm-thick cold-rolled commercial $3 \mathrm{~N}$ copper sheets with the $1 / 2 \mathrm{H}$ condition were used as the test samples. The welding process was performed under load control at the rotation rate of $800 \mathrm{rpm}$ and the transverse speed of $150 \mathrm{~mm} / \mathrm{min}$. A WC-based tool with a concave shoulder $12 \mathrm{~mm}$ in diameter and a cylindrical pin $4 \mathrm{~mm}$ in diameter and $1.9 \mathrm{~mm}$ in length was used. A tilting angle of $3^{\circ}$ was adopted for the welding process and the axial load was controlled at $1.5 \mathrm{t}$. To prevent oxidation of the samples, the FSW process was carried out under flowing Ar gas around the rotation tool. The rapid cooling equipment was 
placed behind the rotating tool with a movement speed the same as the transverse speed. The rapid cooling medium was liquid $\mathrm{CO}_{2}\left(-78{ }^{\circ} \mathrm{C}\right)$ which has a cooling capacity much better than that of other cooling media, such as water and liquid nitrogen. During the entire welding process, the area behind the rotating tool was cooled by the liquid $\mathrm{CO}_{2}$. A K-type thermocouple was placed under the work pieces and set in the groove of the back plate to measure the temperature history of the SZ.

In order to preserve the material flow and freeze the microstructure surrounding the rotating probe, a stop action technique was conducted during the welding process. When the welding process had traveled $\sim 70$ $\mathrm{mm}$, the welding machine's emergency stop was engaged, which immediately stopped the traveling and the rotating of the tool. Liquid $\mathrm{CO}_{2}$ was continuously sprayed on the workpieces, cooling the weld from peak temperature of $441{ }^{\circ} \mathrm{C}$ to less than $100{ }^{\circ} \mathrm{C}$ within about 4.7 s. No previous techniques can quench the keyhole when the weld was stopped during welding at such a high cooling rate. For comparison, the conventional FSW without liquid $\mathrm{CO}_{2}$ cooling was also conducted, and the welded joint was cooled from peak temperature of $512{ }^{\circ} \mathrm{C}$ to less than $100{ }^{\circ} \mathrm{C}$ within about $28.6 \mathrm{~s}$.

The microstructural studies focused on the slice from the center plane of the weld to avoid the more complex flow that occurs near the shoulder and weld root. A schematic diagram of the plan-view sample is shown in Fig. 1a. For preparation of the EBSD measurement, the samples were ground and then electropolished for $60 \mathrm{~s}$ in a solution of $\mathrm{HPO}_{4}: \mathrm{CH}_{4} \mathrm{O}: \mathrm{H}_{2} \mathrm{O}=1: 1: 2$ in volume at $5 \mathrm{~V}$ and $-10{ }^{\circ} \mathrm{C}$. EBSD measurements were conducted using an EDAX-TSL OIM ${ }^{\mathrm{TM}}$ system installed on a field emission scanning electron microscope (FE-SEM). Crystallographic data were obtained from several regions, illustrated as solid squares in Fig. 1b. R1 and R3 lie on the transverse line, exhibiting the microstructure of the advancing side and retreating side of the frozen keyhole, respectively. R2 and R4 lie on the center line of the welded joint, denoting the microstructure ahead and behind the probe, respectively. The $\mathrm{R} 4$ region shows the microstructure that had just been welded. 
The annealing treatment was then performed in an electronic furnace to examine the effect of the post-annealing on the SZ. The R4 region was annealed three times under the same annealing conditions. The annealing condition was $500{ }^{\circ} \mathrm{C}$ for $15 \mathrm{~s}$ followed by a water quench. After each annealing, the EBSD measurement was conducted. The misorientation angle between the two adjacent measurement points was calculated and the cut-off angle for the misorientation analysis was $2^{\circ}$. The substructures in the R4 region before annealing and after three annealing treatments were characterized by transmission electron microscopy (TEM). For the TEM sample preparation, thin polished samples were double-jet electropolished using a solution of $\mathrm{HPO}_{4}: \mathrm{CH}_{4} \mathrm{O}: \mathrm{H}_{2} \mathrm{O}=1: 1: 2$ in volume at $5 \mathrm{~V}$ and $-30{ }^{\circ} \mathrm{C}$.

\section{Results and discussion}

\subsection{Base metal}

EBSD measurement was conducted on the surface of the base metal (BM), and the obtained results including the orientation color map, histogram of the misorientation angle distribution and pole figures of 111 and 011 are shown in Fig. 2, in which the individual grains are colored according to their crystallographic directions parallel to the ND direction. The average grain size of the BM was determined to be $25.0 \mu \mathrm{m}$. A histogram of the misorientation angles in the BM is shown in Fig. 2b. There are two prominent peaks, which is quite different from the random distribution of the cubic crystallites as shown by the black dotted line. The first peak was located at $2^{\circ}$ to $5^{\circ}$, which indicates the dislocation substructures since the BM was received in a work-hardened condition; the second peak was located at $60^{\circ}$ indicated no strong texture and some of the $\Sigma 3$ twin boundaries which is typically observed in copper as annealing twin boundaries. Figure 2c shows the 111 and 011 pole figures of the BM. No significant texture can be found since the BM is the partially annealed sheet. 


\subsection{Microstructure around the keyhole}

Microstructural features including the orientation color map with an enlarged grain boundary map and misorientation angle distribution of the advancing side (R1), ahead of the probe (R2), retreating side (R3) and the SZ immediately behind of the probe (R4) are shown in Fig. 3 and Fig. 4, respectively. On the advancing side (R1 region, Fig. 3a), the initial grains were remarkably elongated to the WD. This indicates that the shear force evolved due to the clockwise rotating probe. The number fraction of low angle boundaries increased to $62 \%$ of the total boundary length (Fig. 4a). According to the grain boundary map, the following three characteristics were found:

(1) The initial grain boundaries, which are indicated by the broad black line in Fig. 3a, have partially serrated morphologies. This is typically observed during the initial stage of discontinuous dynamic recrystallization, as reported by Humphreys and Hatherly (2004).

(2) Some segments of high angle boundaries can be found in the interior of the initial grains. These are not randomly scattered, but clustering can be found as indicated by the dot-line cycle. Some of these are located in the vicinity of the initial grain boundaries where nonhomogeneous plastic deformation preferentially occurs. These nonhomogeneous distributions of high angle boundaries were clarified by Kobayashi et al. (2007) during the initial stage of the continuous dynamic recrystallization in copper.

(3) New grains surrounded by newly formed high angle boundaries, as indicated by the arrow, contain almost no substructures. The absence of a substructure in the fine grains was also reported in severely deformed pure copper. (2) and (3) are interpreted in terms of a grain subdivision usually discribed in the research studies of severely plastic-deformed metals, as reported by Hughes and Hansen (1997).

The microstructure features of the material ahead of the rotating tool (R2) obtained by EBSD measurements are shown in Fig. 3b and Fig. 4b. Compared to the result at position R1, the number fraction of the low angle boundaries slightly decreased to $58 \%$, while that of the high angle boundaries increased. 
Some of the initial grains still have no high angle boundaries. This means that there is no significant difference between the results in regions $\mathrm{R} 1$ and $\mathrm{R} 2$.

When the back of the probe was observed, a significant change from the front side (R1 and R2) can be found. The grain structure and the histogram of the misorientation angle obtained by EBSD measurements of the retreating side of the back of the tool (R3 region) are given in Fig. 3c and Fig. 4c. The orientation color map and the boundary map showed a uniform distribution of fine grains which are elongated in the direction roughly tangential to the columnar surface of the probe. The grain size ranged from $0.1 \mu \mathrm{m}$ to 0.7 $\mu \mathrm{m}$. According to the misorientation angle distribution, the ultrafine elongated grains are mainly surrounded by high angle boundaries. The number fraction of the low angle boundaries further decreased to $28 \%$ (Fig. 4c). These features of the microstructure at location R3 are very similar to the severely deformed microstructure where the grain subdivision was almost completed.

A high density of high angle boundaries can also be found on the advancing side of the backward region of the probe. The EBSD measurement results of the SZ immediately behind the probe (R4) are given in Fig. 3d and Fig. 4d. The grain structure still maintains a fine grained structure, but their shape was transformed into an equiaxial one (Fig. 3d). The mean grain size was determined to be $1.5 \mu \mathrm{m}$ with the lower aspect ratio of 1.2. The number fraction of the low angle boundaries was $35 \%$ which is similar to that at location R3 (Fig. 4d).

One of the characteristic findings in the grain structure around the frozen keyhole is that the grain refinement was highly achieved in the back of the probe. The grain subdivision sufficient for a uniform grain structure mainly takes place after the probe passes through. It is well known that the grain subdivision proceeds with an increasing strain, so the acceleration of the grain subdivision in the back indicates that the plastic deformation should be localized at the end of the rotation of the material flow. 
In order to reveal the orientation nature of the SZ, which was just welded during the plastic deformation stage, a local texture analysis the R4 region was performed. Before considering the texture analysis, it is necessary to briefly discuss the geometry of the deformation during the stirring. Fonda and Knipling (2011) certified that the SZ exhibited textures due to simple shear around the probe. Montheillet et al. (1985) clarified that the shear textures are conventionally defined in terms of the crystallographic plane $\{h k l\}$ and direction $\langle u v w\rangle$. The crystallographic plane $\{h k l\}$ and direction $\langle u v w\rangle$ are aligned with the shear plane (probe surface) and shear direction (SD, probe surface tangent on ND plane), respectively. The predominant shear deformation introduced by the rotating tool should vary as a function of the position around the probe, i.e., for the R4 region, the shear direction and shear plane normal (SPN) are almost parallel to the TD and WD, respectively.

The 111 and 011 pole figures of the R4 region are shown in Fig. 5. The SZ immediately behind the probe showed a texture predominantly consisting of the symmetrical $A(\overline{111})[110] / \bar{A}(\overline{111})[\overline{110}]$ component in which the rotation tangent (TD) and radius (WD) directions were $\langle 110\rangle$ and $\langle 111\rangle$, respectively. This component can be categorized as the $A / \bar{A}$ simple shear texture according to the assumption for the plastic shear flow that the rotation tangent and the radius directions are parallel to the shear direction and the shear plane normal, as reported by Fonda and Knipling (2011). This kind of shear texture was frequently observed in the SZ near the probe of the FSW of FCC materials, as reported by Mironov et al. (2011) for S31254 super austenitic stainless steel and by Jeon et al. (2011) for single crystal S304 austenitic stainless steel. It should be noted that highest orientation concentration can be found on the TD in the 011 pole figure. This means the existence of a weak $\{h k l\}\langle 110\rangle$ fiber texture which is found in the austenitic stainless steel joint. This fibre texture is typical for the simple shear texture, as reported by Prangnel and Heason (2005). 


\subsection{Microstructure in the SZ}

Figure 6 shows the microstructure features of the SZ located at $5 \mathrm{~mm}$ behind the frozen keyhole, which exhibited the final microstructure of the SZ obtained by the RC-FSW. The obtained SZ exhibited ultrafine equiaxial grains with the mean grain size of $1.7 \mu \mathrm{m}$, and the number fraction of the low angle boundaries was $40 \%$. The $A / \bar{A}$ shear texture was detected. These features are very similar to that observed at location R4. This means that the deformation structure, which was produced by the rotating probe, was almost completely frozen by using the liquid $\mathrm{CO}_{2}$ cooling.

For comparison, the microstructure features of the SZ located $5 \mathrm{~mm}$ behind the keyhole, which exhibited the final microstructure of the SZ obtained by the conventional FSW without rapid cooling, are shown in Fig. 7. The SZ showed an equiaxed and coarse structure with annealing twins, which is very different from that of the SZ obtained by RC-FSW. The mean grain size of the SZ significantly coarsened to $19 \mu \mathrm{m}($ Fig. 7a). The histogram of the misorientation angle distribution shows a lower density of low angle boundaries indicating a static recrystallization. The number fraction of the high angle boundaries increased to $91 \%$, and $34 \%$ of them was determined as twin boundaries (Fig. 7b). The SZ shows a texture consisting of a partial $A(111)[110]$ shear texture and $(101)[010]$ texture. These results indicate that the post-annealing effect should not be ignored in the investigation of grain structure formation during the FSW.

If the post-annealing effect is provided by a completely static reaction, the microstructure in the conventional FSW joint should be reproduced by the post-weld heat treatment of the RC-FSW joint. The subsequent annealing treatment was performed on the frozen keyhole of the RC-FSW joint. The R4 region was examined by EBSD measurement after each annealing treatment at $500{ }^{\circ} \mathrm{C}$ for $15 \mathrm{~s}$. The obtained orientation color maps for each annealing treatment are shown in Fig. 8, and the mean grain sizes before annealing and after each annealing are plotted in Fig. 9. Data from Fig. 9 were evaluated by counting only the high angle boundaries. It was found that the equiaxial morphology of the grains does not change, but the 
grain size significantly changed, which can be categorized as normal grain growth. After three annealings, the mean grain size of the $\mathrm{R} 4$ region coarsened from $1.5 \mu \mathrm{m}$ to $10.7 \mu \mathrm{m}$, reaching nearly that of the conventional FSW without rapid cooling.

The grain size distribution in the dislocation-rich region and dislocation-free region before annealing and after each annealing are plotted in Fig. 10. The sample before the annealing shows a one-peak distribution in both types of grains and this feature was maintained even after the annealing processes. The peak positions of both distributions did not significantly change when compared in the same sample. This well corresponded with the morphology observation in Fig. 8 where a continuous change was indicated. The grains with a low dislocation density grow slightly faster than that of the grains with a relatively high dislocation density. This result should be related to the discontinuous change in texture as shown in Fig. 7

In order to investigate the post-annealing effect on the evolution of the substructure in the grains, TEM observations of the R4 region were performed before the annealings and after three annealings, and the obtained results are shown in Fig. 11. The sample before annealing showed that dislocation cells and tangled dislocations, which were generated in the plastic deformation stage, can be detected in the SZ. This substructure should correspond to the low angle boundaries detected by the EBSD measurement shown in Fig. 4d. After the three annealings, due to the recovery and static recrystallization, the dislocation structure disappeared and large twins appeared. Xue et al. (2013) estimated that this kind of twin with fewer dislocations around it was usually identified as an annealing twin. This observation indicates that the post-annealing effect resulted in the disappearance of the substructures and the grain coarsening.

Although the change in the grain structure during the post-welded heat treatment looks like a continuous behavior, the texture shows a discontinuous change. Additional information about the change during the post-annealing is needed to clarify what happened during the post-annealing. One of the critical distinctions between the continuous and discontinuous recrystallizations is the occurrence of selective nucleation and/or 
grain growth. During the early stage of recrystallization, the dominant driving force of the boundary migration is the difference in the density of the lattice defects in the grains, so the selectively grown grains should have fewer low angle boundaries. Therefore, these dislocation-free grains with few misorientation angles of less than $2^{\circ}$ were separated from Fig. 8c, and their inverse orientation color map is shown in Fig. 12a. These dislocation-free grains have a mixed microstructure consisting of both fine and large grains. The orientation data of the dislocation-free grains are plotted in the 111 and 011 pole figures as shown in Fig. 12b, and it is noteworthy that a typical (101) [010] texture was detected. Figure 13 shows the 111 and 011 pole figures plotted from Fig. 8c, and the (101) [010] texture was generated after three annealings. This is clear proof of the selective grain growth by post-annealing.

An interesting point is that the discontinuous recrystallization as a discontinuous change in texture happens although normal grain growth is revealed. This should be due to the complicated strain pass during the FSW. When the materials start to stir, the velocity of the metal flow increases and there should be a velocity gradient distribution. This means that the strain rate and the temperature gradient during the FSW is not constant. The behavior of the recrystallization is determined by the deformation conditions such as temperature, strain rate and strain. It is difficult to clearly distinguish whether discontinuous and continuous recrystallizations occur during the FSW process. Actually, some of the behaviors for the discontinuous recrystallization were observed in this study; they include serration of the initial grain boundaries and the formation of annealing twins after recrystallization. It can be concluded that the post-annealing provides a significant effect that is not only the grain size change, but also the texture change by a mixture of the continuous and discontinuous recrystallizations. The significant change by the post-annealing effect means that control of the cooling process during the FSW should be one of the important issues to manage the microstructure and mechanical properties of the joints. 


\section{Conclusions}

To clarify the microstructure evolution during the FSW, a stop action technique with liquid $\mathrm{CO}_{2}$ cooling and subsequent annealing were adopted to significantly separate the plastic deformation stage and the post-annealing stage as much as possible. The experiments clarified characteristic recrystallization with the combination of continuous and discontinuous processes which cannot be found in the conventional plastic working processes. The main conclusions are summarized as follows:

1. During the plastic deformation stage of the FSW, the microstructure formation in the SZ was determined by grain subdivision, which separated the large initial grains by the deformation induced boundaries. The SZ immediately behind the probe showed the mean grain size of $1.5 \mu \mathrm{m}$ with a large quantity of low angle boundaries and a symmetrical shear texture.

2. The subsequent annealing treatments on the SZ reproduced the static restoration of the SZ caused by the post-annealing effect after the conventional FSW process. The static recrystallization including the mixture of continuous and discontinuous recrystallizations caused the normal grain growth and discontinuous textural change. When the grains in the SZ were categorized as to having low angle boundaries or not, these two groups separately showed the normal grain growth. The grain growth rate of the grains without a substructure was slightly faster than that with a substructure, which make the texture evolution show a discontinuous change.

3. The recrystallized-like structure in the SZ obtained by the annealing treatment is similar as that of the SZ obtained by the conventional FSW. The static restoration caused by the post-annealing effect can significantly affect the microstructure which is produced by the plastic deformation, and it should not be ignored when discussing the microstructure evolution of the FSW. 


\section{Acknowledgments}

The authors are thankful for the financial support of the project for heterostructure control from the Japan

Science and Technology Agency (JST), the Priority Assistance for the Formation of Worldwide Renowned Centers of Research-The Global COE Program (Project: Center of Excellence for Advanced Structural and Functional Materials Design) and the Cooperative Research Project of Nationwide Joint from the Ministry of Education, Culture, Sports, Science and Technology (MEXT), Japan, and a Grant-in-Aid for Science Research from the Japan Society for Promotion of Science.

\section{References}

Fonda, R.W., Bingert, J.F., 2007. Texture variations in an aluminum friction stir weld. Scr. Mater. 57, 1052-1055.

Fonda, R.W., Knipling, K.E., 2011. Texture development in friction stir welds. Sci. Technol. Weld. Join. 16, 288-294.

Humphreys, F.J., Hatherly, M., 2004. Recrystallization and Related Annealing Phenomena, second ed. Pergamon Press, Oxford, pp. 418-421.

Hughes, D.A., Hansen, N., 1997. High angle boundaries formed by grain subdivision mechanisms. Acta Mater. 45, 3871-3886.

Jeon, J.J., Mironov, S., Sato, Y.S., Kokawa, H., Park, S.H.C., Hirano, S., 2013. Grain structure development during friction stir welding of single-crystal austenitic stainless steel. Metall. Mater. Trans. A $44,3157-3166$.

Jeon, J.J., Mironov, S., Sato, Y.S., Kokawa, H., Park, S.H.C., Hirano, S., 2011. Friction stir spot welding of single-crystal austenitic stainless steel. Acta Mater. 59, 7439-7449. 
Kobayashi, C., Sakai, T., Belyakov, A., Miura, H., 2007. UltraFine Grain Development in Copper during Multidirectional forging at 195 K. Phil. Mag. Lett., 87, 751-766.

Mishra, R.S., Ma, Z.Y., 2005. Friction stir welding and processing. Mater. Sci. Eng. R 50, 1-78.

Mironov, S., Masaki, K., Sato, Y.S., Kokawa, H., 2013. Texture produced by abnormal grain growth in friction stir-welded aluminum alloy 1050. Metall. Mater. Trans. A 44, 1153-1157.

Mironov, S., Inagaki, K., Sato, Y.S., Kokawa, H., 2015. Microstructural evolution of pure copper during friction-stir welding. Philos. Mag. 95, 367-381.

Mironov, S., Inagaki, K., Sato, Y.S., Kokawa, H., 2014. Development of grain structure during friction-stir welding of Cu-30Zn brass. Philos. Mag. 94, 3137-3148.

Mironov, S., Sato, Y.S., Kokawa, H., Inoue, H., Tsuge, S., 2011. Structural response of superaustenitic stainless steel to friction stir welding. Acta Mater. 59, 5472-5481.

Mironov, S., Sato, Y.S., Kokawa, H., Inoue, H., Tsuge, S., 2011. Structural response of superaustenitic stainless steel to friction stir welding. Acta Mater. 59, 5472-5481.

Montheillet, F., Gilormini, P., Jonas, J.J., 1985. Relation between axial stress and texture development during torsion testing. Acta Metall. 33, 705-717.

Prangnel, P.B., Heason, C.P., 2005. Grain structure formation during friction stir welding observed by the 'stop action technique'. Acta Mater. 53, 3179-3192.

Sato, Y.S., Nelson, T.W., Sterling, C.J., 2005. Recrystallization in type 304L stainless steel during friction stirring. Acta Mater. 53, 637-645.

Suhuddin, U.F.H.R., Mironov, S., Sato, Y.S., Kokawa, H., 2010. Grain structure and texture evolution during friction stir welding of thin 6016 aluminum alloy sheets. Mater. Sci. Eng. A 527, 1962-1969. 
Thomas, W.M., Nicholas, E.D., Needham, J.C., Murch, M.G., Temple-Smith, P., 1991. International Patent Application No. PCT/GB92/02203.

Xu, N., Ueji, R., Fujii, H., 2014. Enhanced mechanical properties of 70/30 brass joint by rapid cooling friction stir welding. Mater. Sci. Eng. A 610, 132-138.

Xue, P., Xiao, B.L., Ma, Z.Y., 2013. Enhanced strength and ductility of friction stir processed Cu-Al alloys with abundant twin boundaries. Scr. Mater. 68, 751-754. 


\section{Table caption}

Table 1 A summary of microstructure features in SZ of FSP/FSWed FCC metals and alloys.

\section{Figure Captions}

Fig. 1 Schematic illustration of the frozen keyhole, showing (a) the selected plan-view section and (b) the locations (R1, R2, R3 and R4) of the EBSD measurement. The plate-normal direction, welding direction and transverse direction are indicated by ND, WD and TD, respectively.

Fig. 2 EBSD measurement results of the BM including (a) the ND orientation color map with the color code triangle shown in the bottom right corner, (b) the histogram of the misorientation angle distribution and (c) the 111 and 011 pole figures. The dotted line in the histogram shows Brandon's distribution for random texture.

Fig. 3 ND orientation color maps at different positions around frozen keyhole. (a) R1, (b) R2, (c) R3 and (d) R4. The boundary color maps of the selected regions in R1, R2 and R3 are also exhibited. In the boundary color map, low angle boundaries $\left(2^{\circ}\right.$ to $\left.15^{\circ}\right)$, high angle boundaries (larger than $\left.15^{\circ}\right)$ and twin boundaries are depicted as green, black and red lines, respectively.

Fig.4 Histograms of the misorientation angle at different positions around the frozen keyhole. (a) R1, (b) R2, (c) R3 and (d) R4.

Fig. 5111 and 011 pole figures obtained at position R4, (a) pole figures obtained by EBSD measurement, (b) exact pole figures in simple shear frame.

Fig. 6 EBSD results including (a) ND orientation colour map, (b) misorientation angle distribution and (c) the 111 and 011 pole figures of the SZ obtained by RC-FSW.

Fig. 7 EBSD results including (a) ND orientation color map, (b) misorientation angle distribution and (c) the 111 and 011 pole figures of the SZ obtained by conventional FSW. (d) exact 111 and 011 pole figures of (101) [010] orientation.

Fig. 8 ND orientation color maps obtained by EBSD measurements under the same annealing conditions by (a) one annealing; (b) two annealings and three annealings. 
Fig. 9 Mean grain size of position R4 before annealing and after each annealing process.

Fig. 10 Grain size distribution of the dislocation-rich region and dislocation-free region in position R4 before annealing and after each annealing process.

Fig. 11 Bright-field TEM images of the position R4, (a) before annealing and (b) after three annealings.

Fig. 12 EBSD results of the dislocation-free grains which separated from Fig. 8c, (a) ND orientation color map and (b) 111 and 011 pole figures.

Fig. 13111 and 011 pole figures of position R4 after three annealings. 


\begin{tabular}{|c|c|c|c|c|c|c|c|}
\hline & Materials & $\begin{array}{l}\text { Rotation rate } \\
\text { (rpm) }\end{array}$ & $\begin{array}{l}\text { Traverse speed } \\
(\mathrm{mm} / \mathrm{min})\end{array}$ & $\begin{array}{c}\text { Grain size } \\
(\mu \mathrm{m})\end{array}$ & Texture & $\begin{array}{c}\text { Recrystallization } \\
\text { mechanism }\end{array}$ & Reference \\
\hline & A1050 & 2000 & 600 & 1.1 & $\{112\}<110>$ & N/A & $\begin{array}{c}\text { Mironov } \\
\text { et al. } \\
\text { (2013) } \\
\end{array}$ \\
\hline & $\begin{array}{c}\text { Aluminu } \\
\text { m alloy }\end{array}$ & 180 & 102 & Not shown & $\{112\}<110>$ & $\mathrm{DRX}^{*}$ & $\begin{array}{c}\text { Fonda } \\
\text { and } \\
\text { Bingert } \\
\text { (2007) }\end{array}$ \\
\hline & & 3000 & 2000 & 12 & $\begin{array}{l}\{112\}<110> \\
\{100\}<001>\end{array}$ & $\begin{array}{c}\text { DRX, } \\
\text { Grain subdivision }\end{array}$ & $\begin{array}{c}\text { Suhuddin } \\
\text { et al. } \\
(2010) \\
\end{array}$ \\
\hline & & 200 & 120 & 1 & $\{111\}<110>$ & DRX & $\begin{array}{c}\text { Mironov } \\
\text { et al. } \\
\text { (2015) }\end{array}$ \\
\hline & & 1000 & 120 & 27 & $\{111\}$ fiber & DRX & $\begin{array}{c}\text { Mironov } \\
\text { et al. } \\
(2015)\end{array}$ \\
\hline & $\begin{array}{l}\text { Copper } \\
\text { alloy }\end{array}$ & & & & & & \\
\hline & & 600 & 200 & 10 & $\begin{array}{l}\{111\}<211> \\
\{100\}<001>\end{array}$ & N/A & $\begin{array}{c}\text { Xu et al. } \\
\text { (2014) }\end{array}$ \\
\hline & & 600 & 120 & 0.3 & $\{111\}<110>$ & DRX & $\begin{array}{c}\text { Mironov } \\
\text { et al. } \\
(2014)\end{array}$ \\
\hline \multirow{3}{*}{$\begin{array}{c}\text { Austenite } \\
\text { stainless } \\
\text { steel }\end{array}$} & & 600 & 50 & 4.2 & $\{110\}<001>$ & DRX & $\begin{array}{c}\text { Jeon et al. } \\
\text { (2013) }\end{array}$ \\
\hline & SUS304 & 400 & 30 & 4.2 & $\{110\}<001>$ & $\begin{array}{c}\text { DRX, } \\
\text { Grain subdivision }\end{array}$ & $\begin{array}{c}\text { Mironov } \\
\text { et al. } \\
(2011)\end{array}$ \\
\hline & SUS304L & 450 & 120 & $6-9$ & $<100>$ fiber & DRX, SRX** & $\begin{array}{c}\text { Sato et al. } \\
\text { (2005) }\end{array}$ \\
\hline
\end{tabular}

* DRX: Dynamic recrystallization; ** SRX: Static recrystallization 


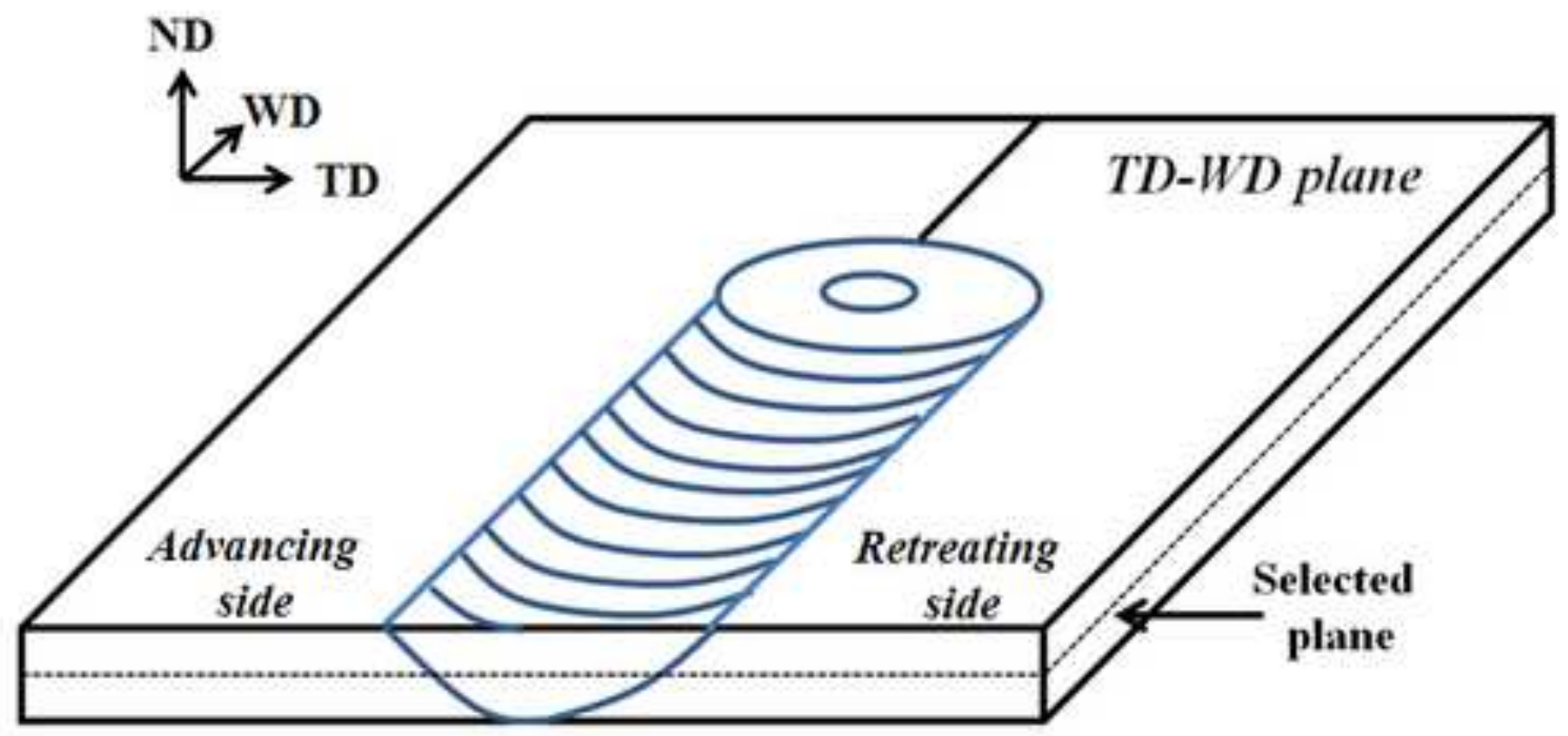

(a)

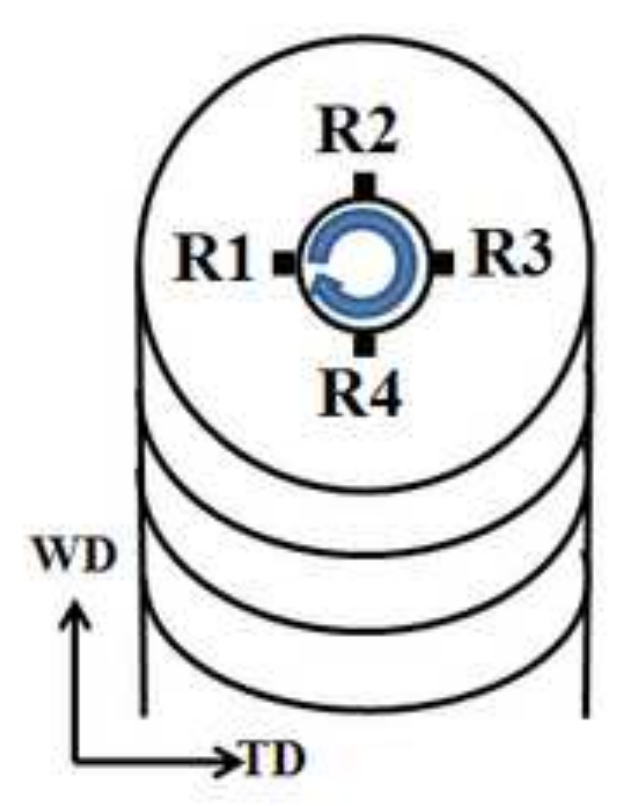

(b) 
(a)

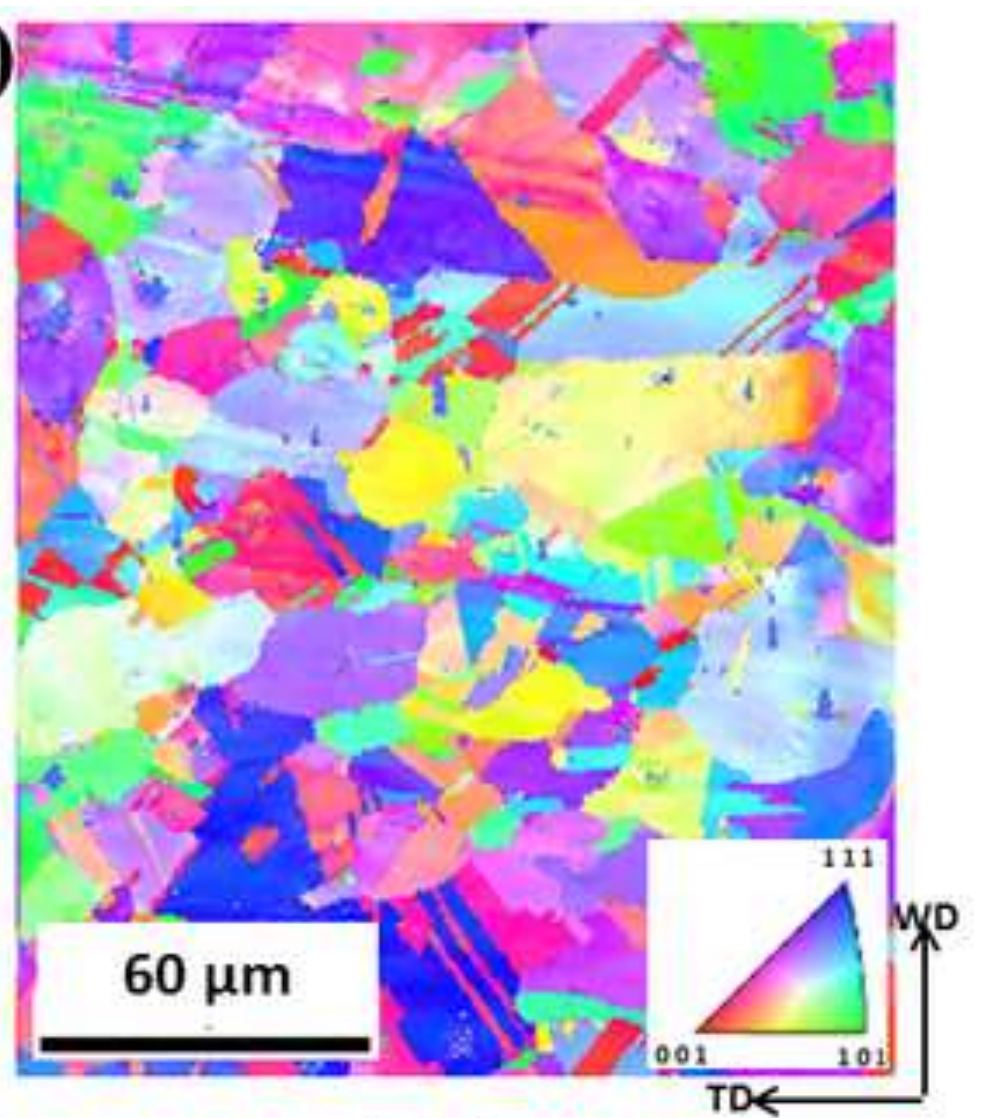

(c)
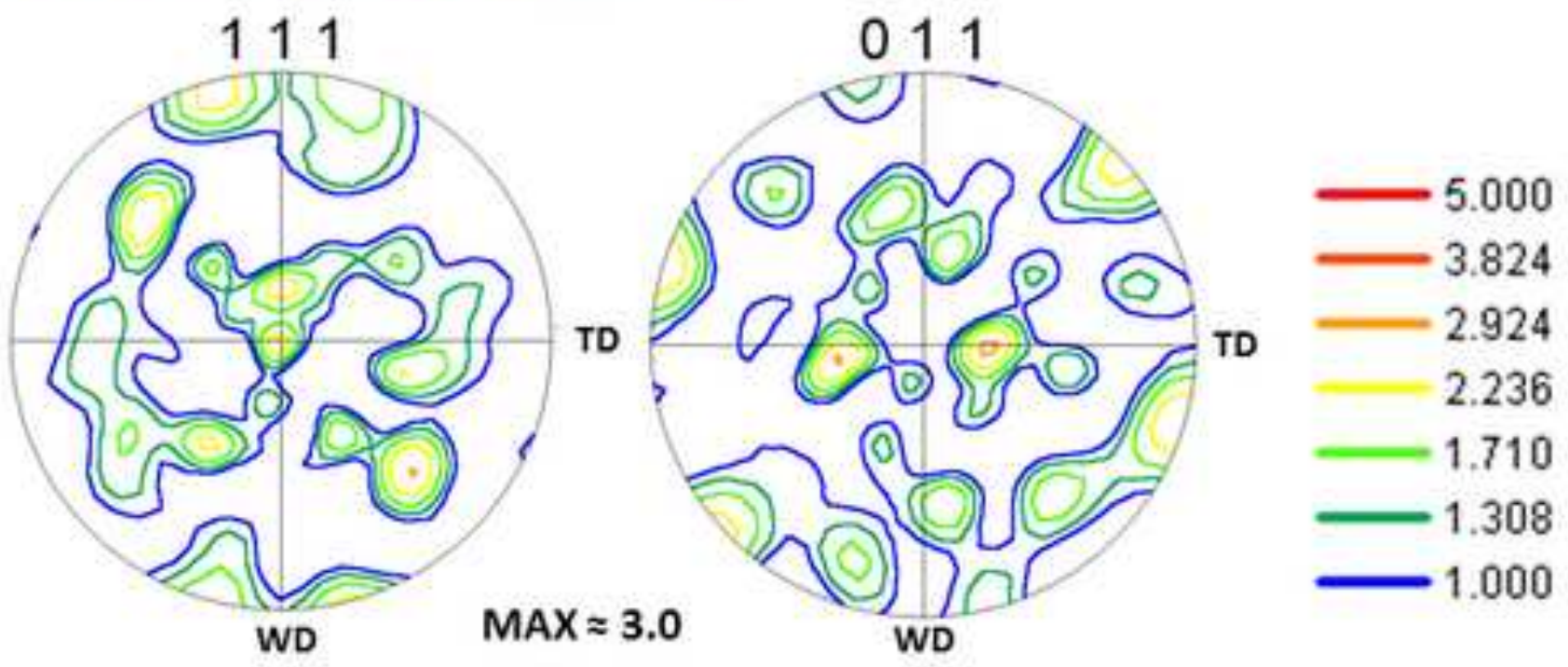

(b)

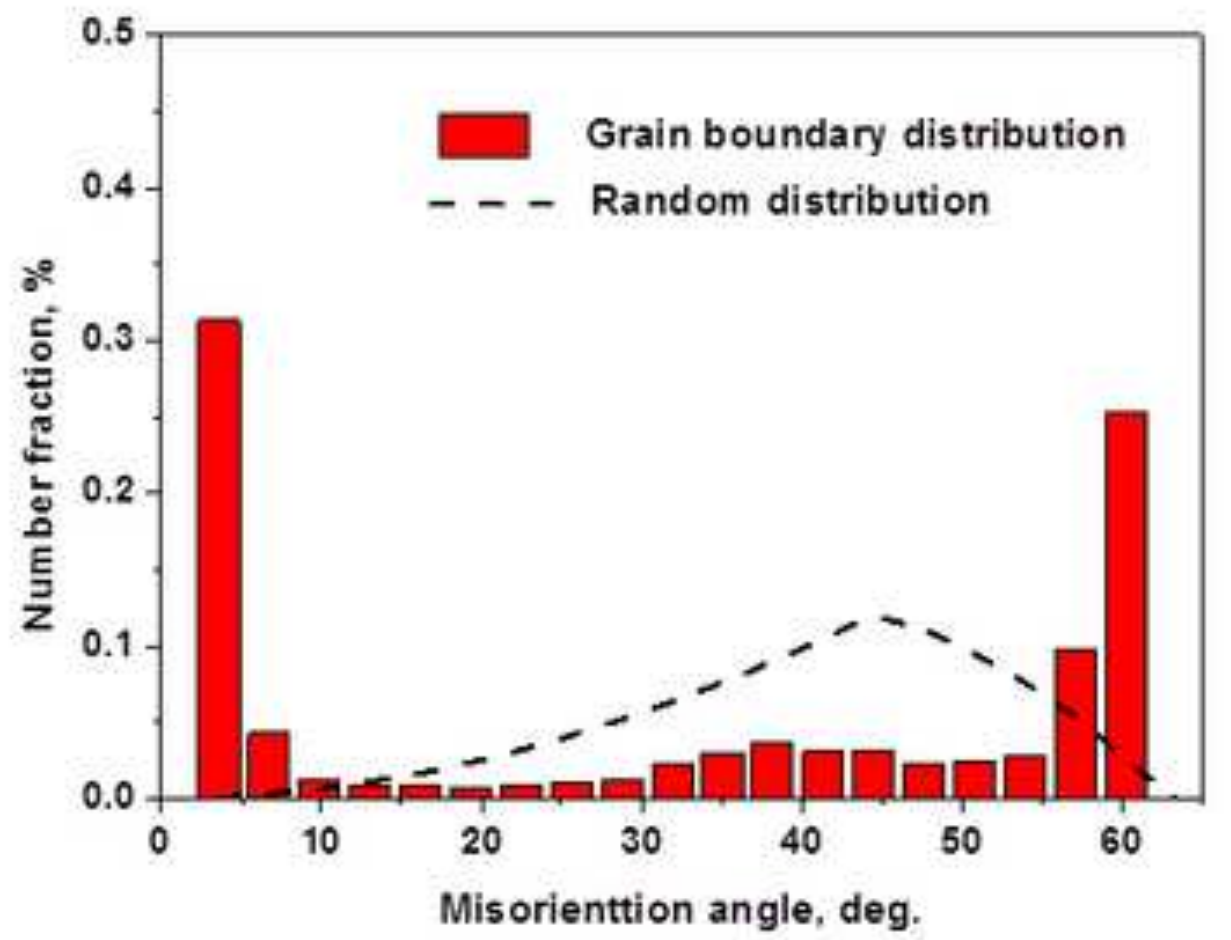

Misorienttion angle, deg. 
(a)

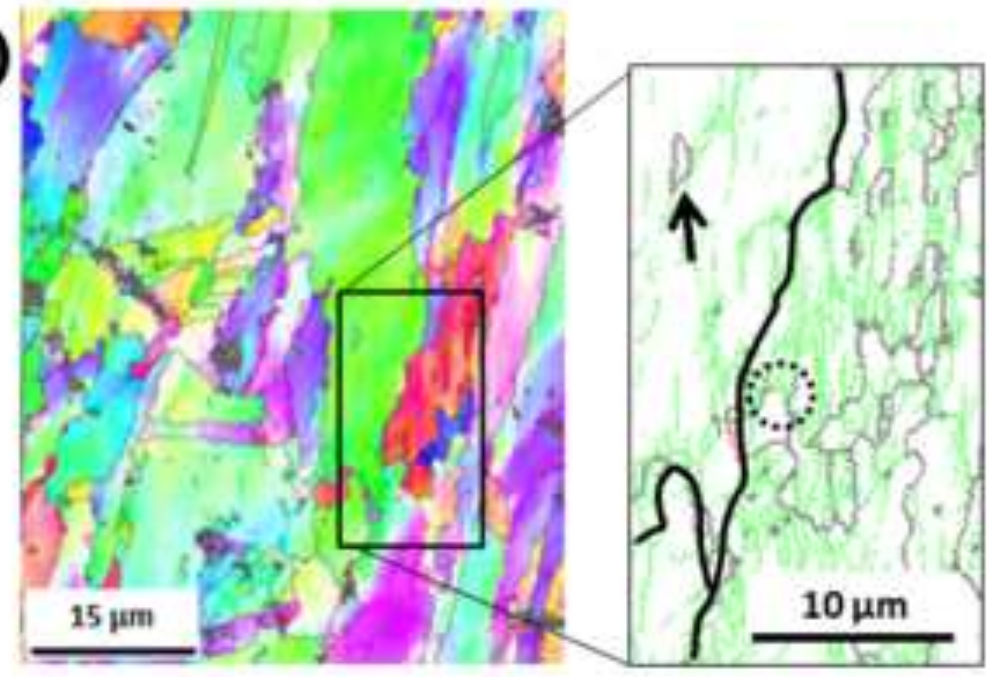

(c)

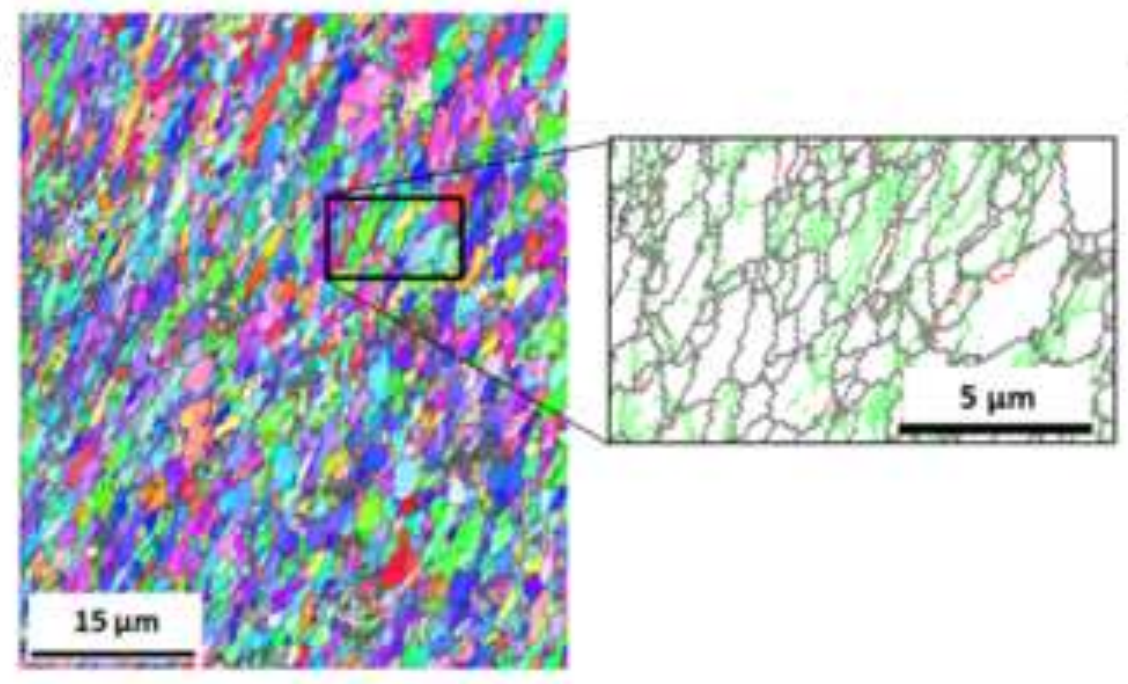

(b)

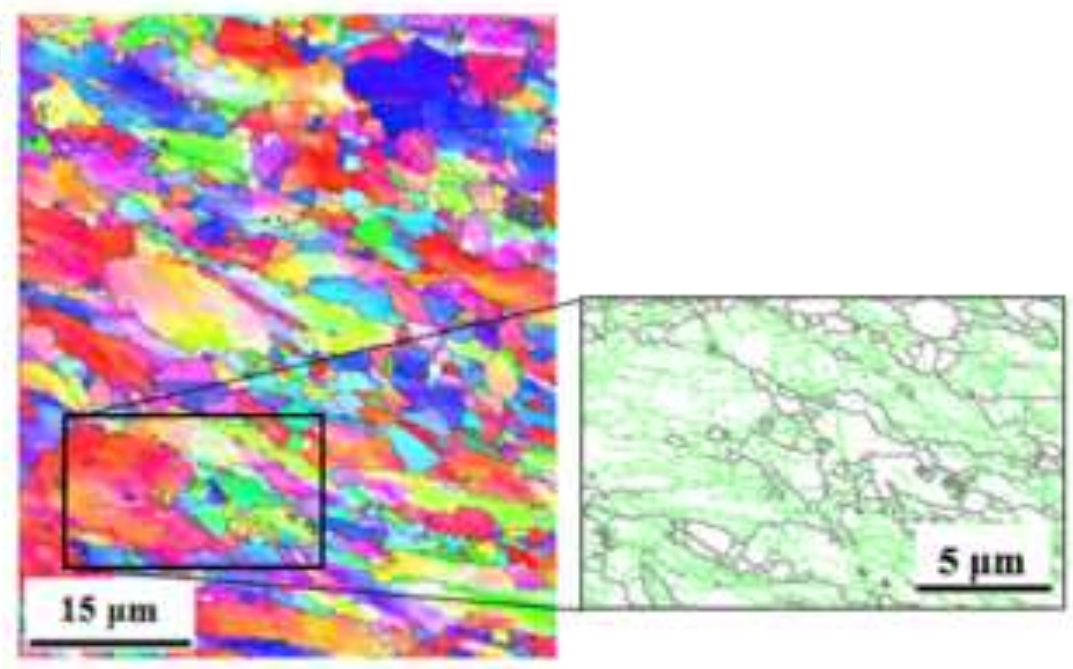

(d)
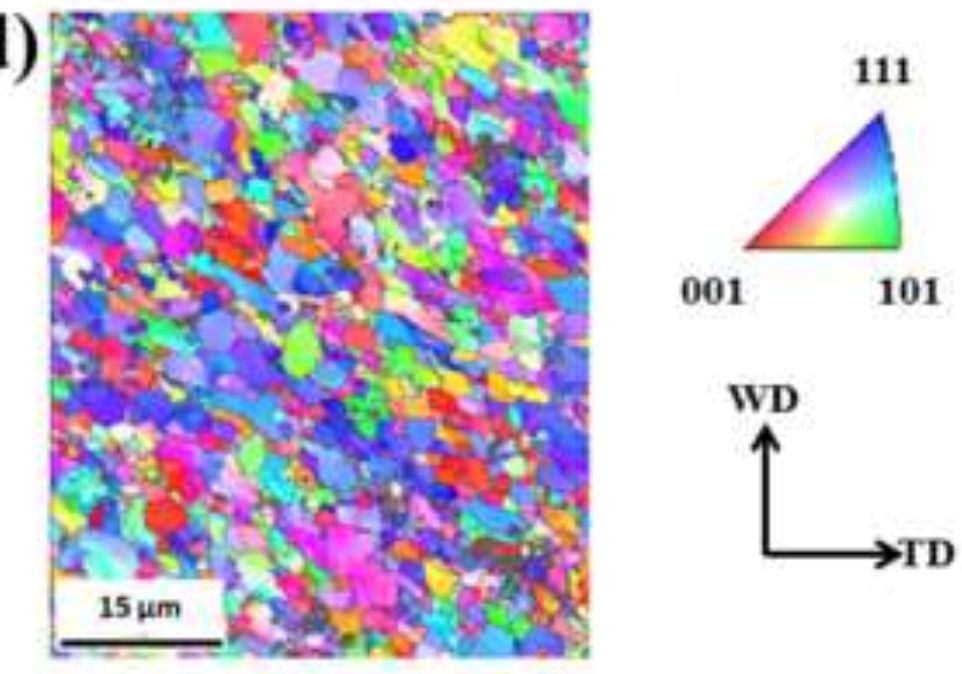

ri 
(a)

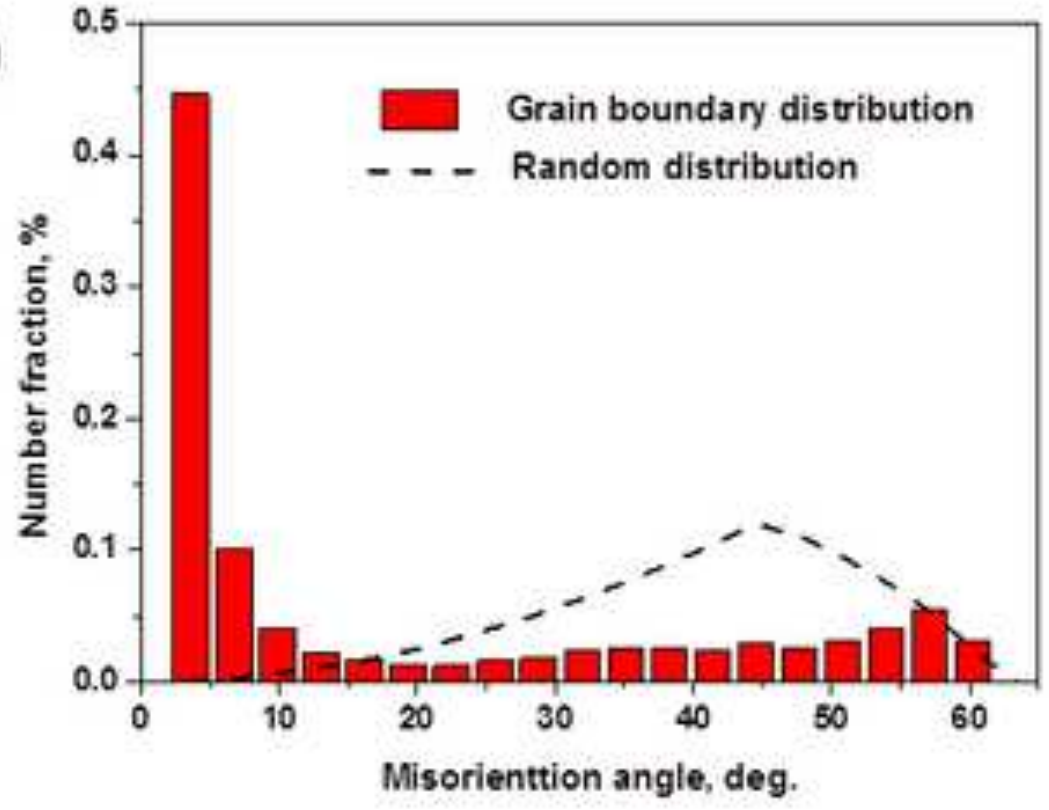

(c)

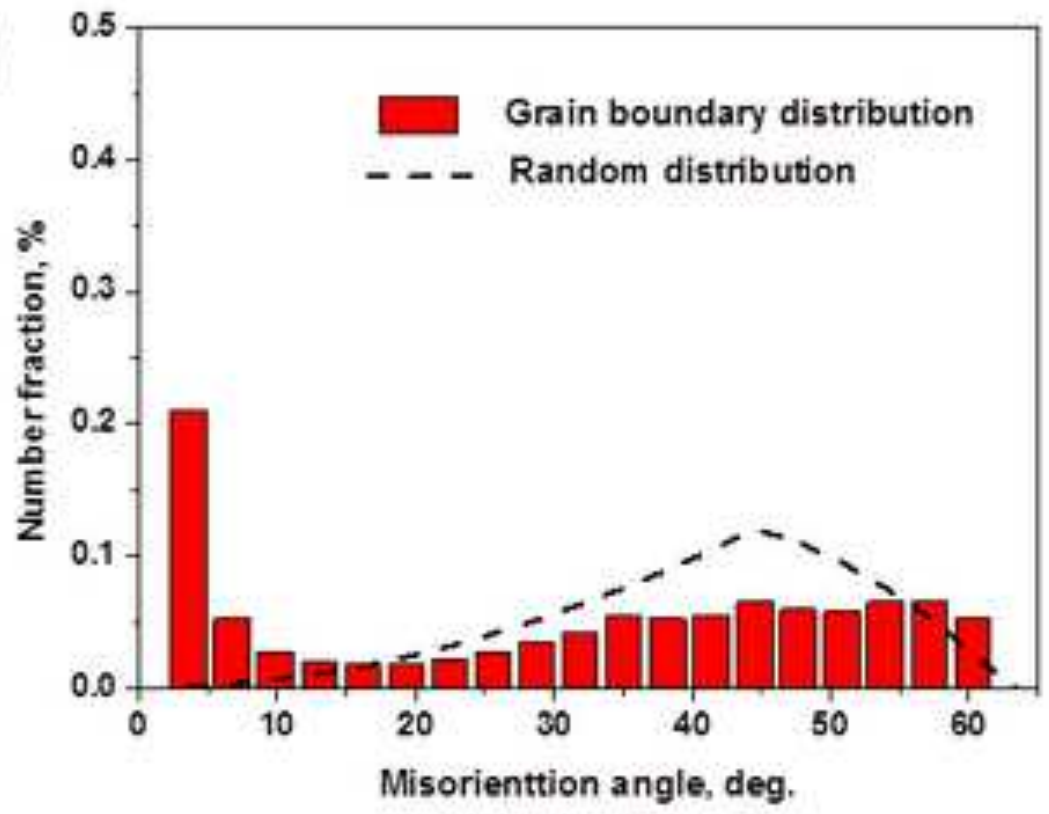

(b)

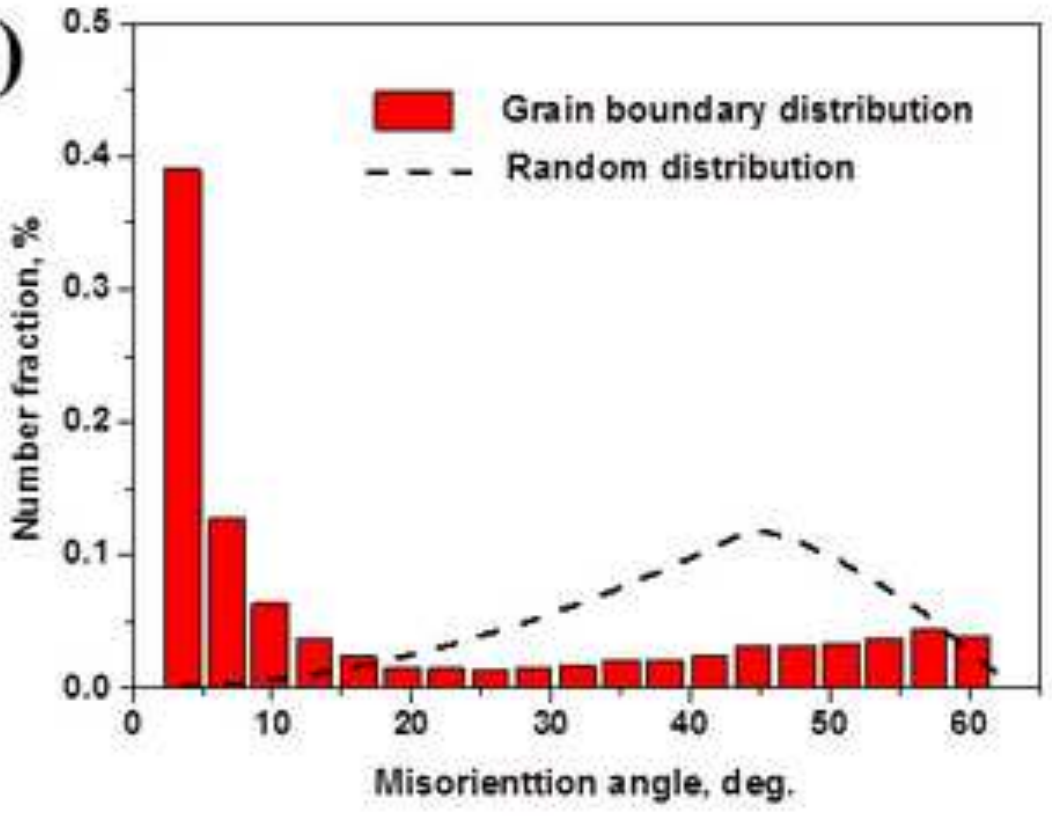

(d)

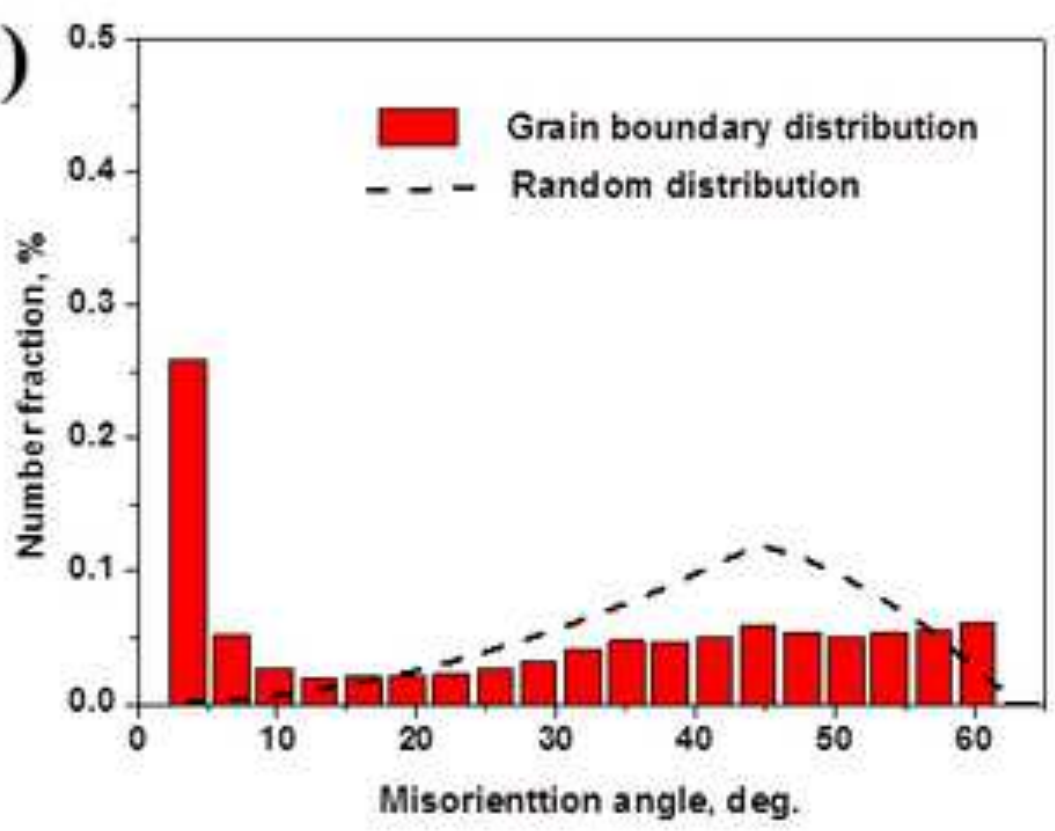



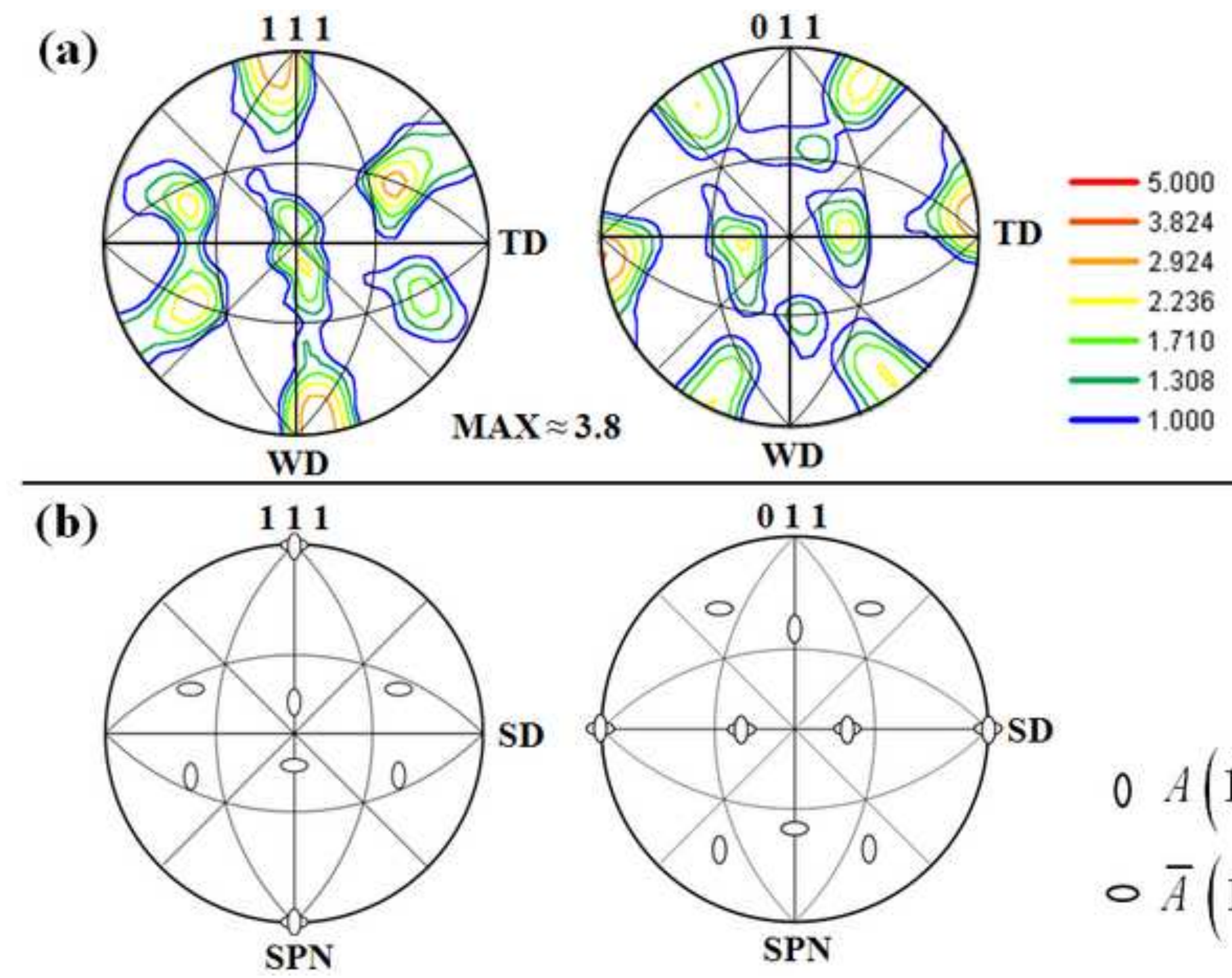

$$
\begin{aligned}
& 0 A(\overline{111})[110] \\
& \circ \bar{A}(\overline{111})[\overline{110}]
\end{aligned}
$$


(a)

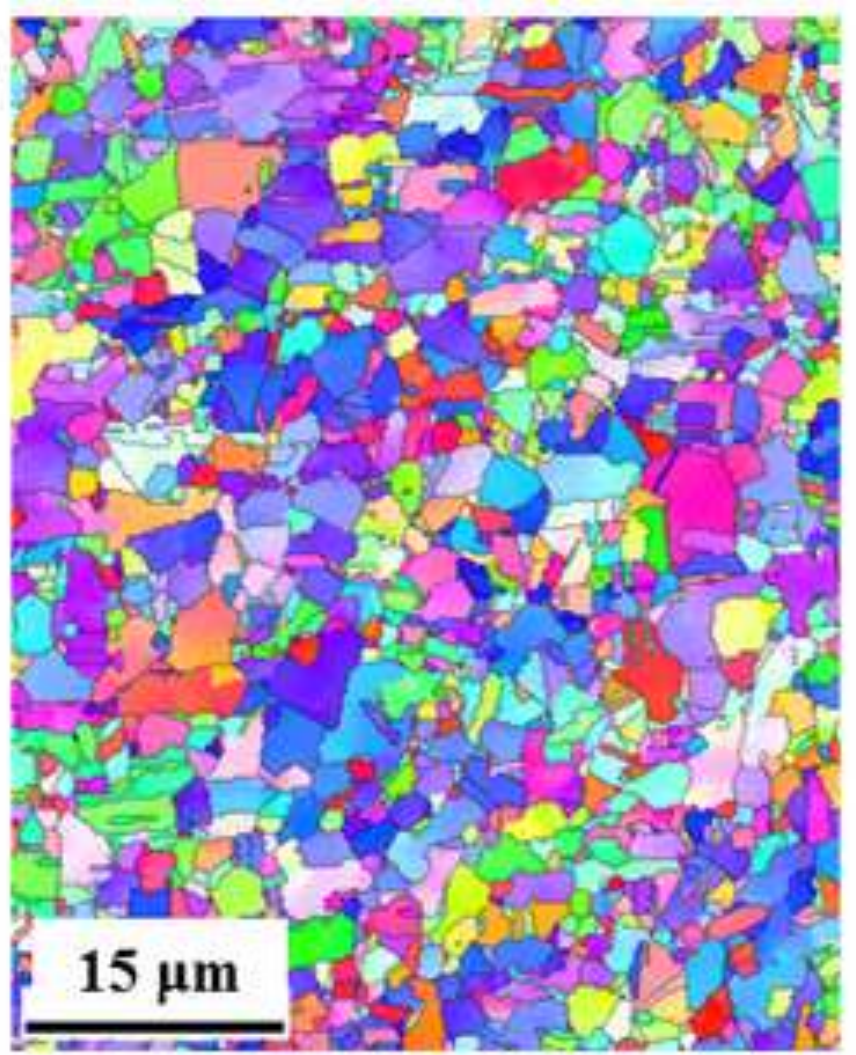

(c)

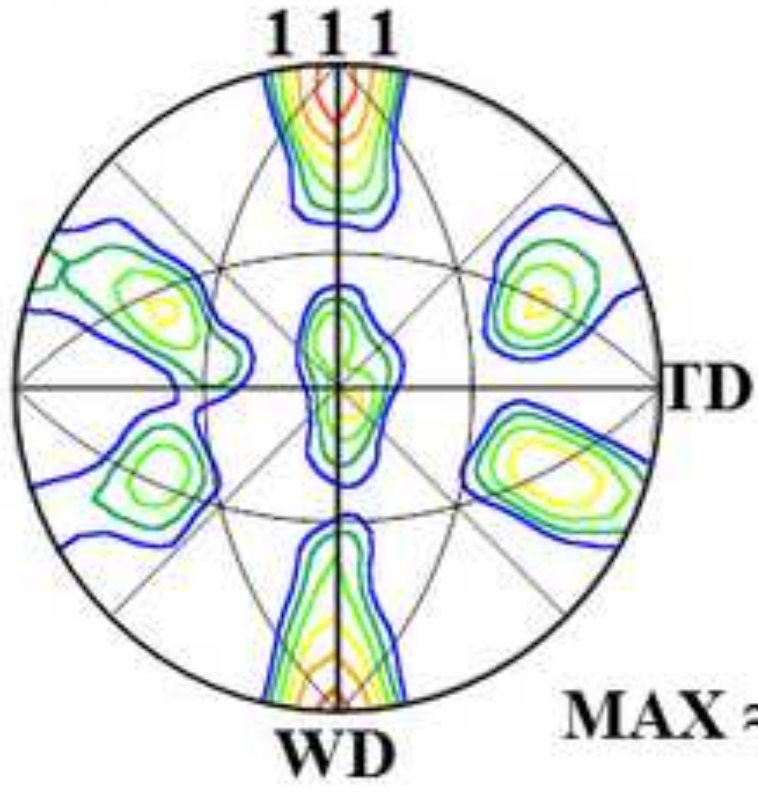

(b)
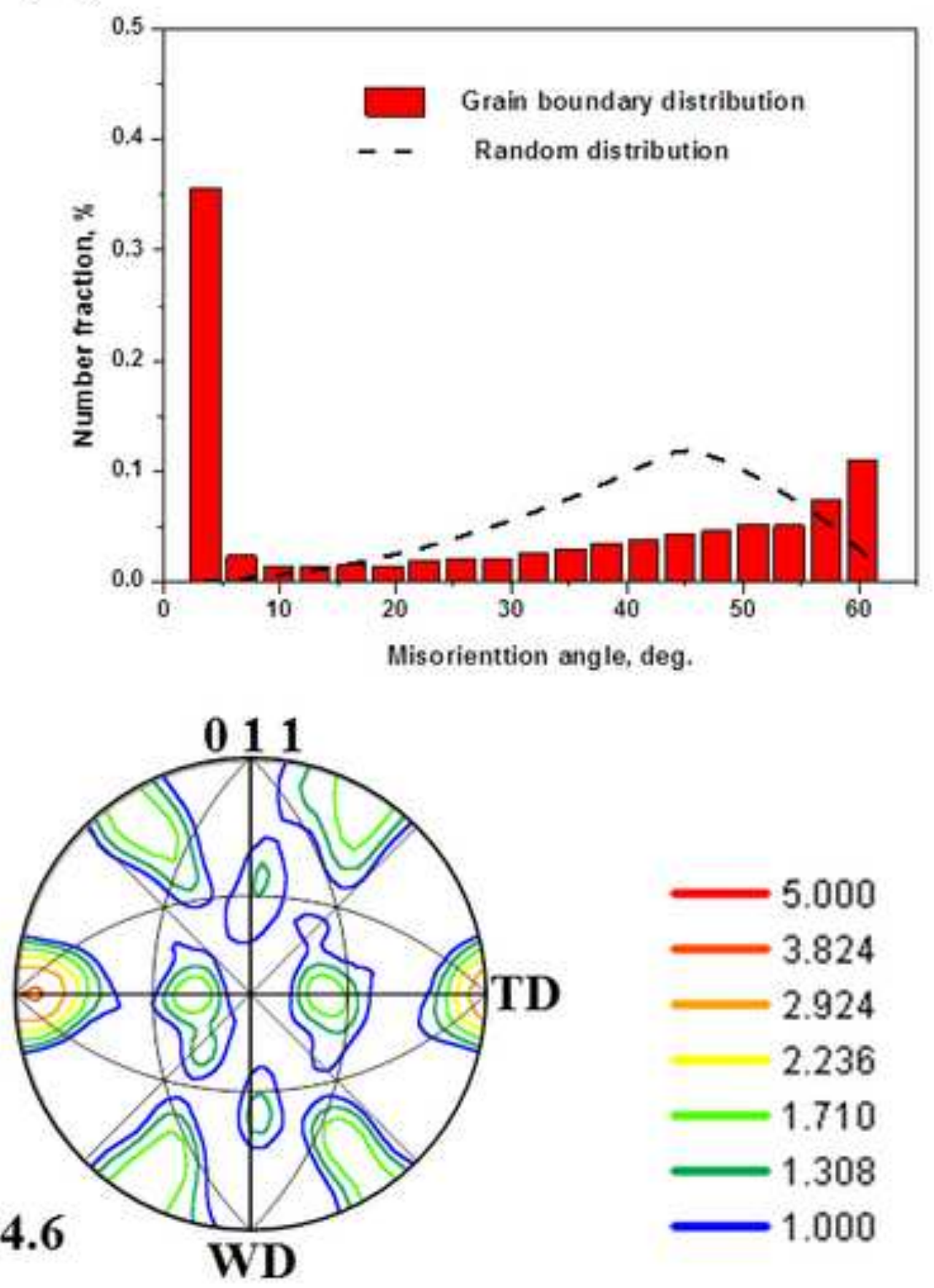

$-3.824$

2.924

2.236

$-1.710$

$-1.308$

$-1.000$ 
(a)

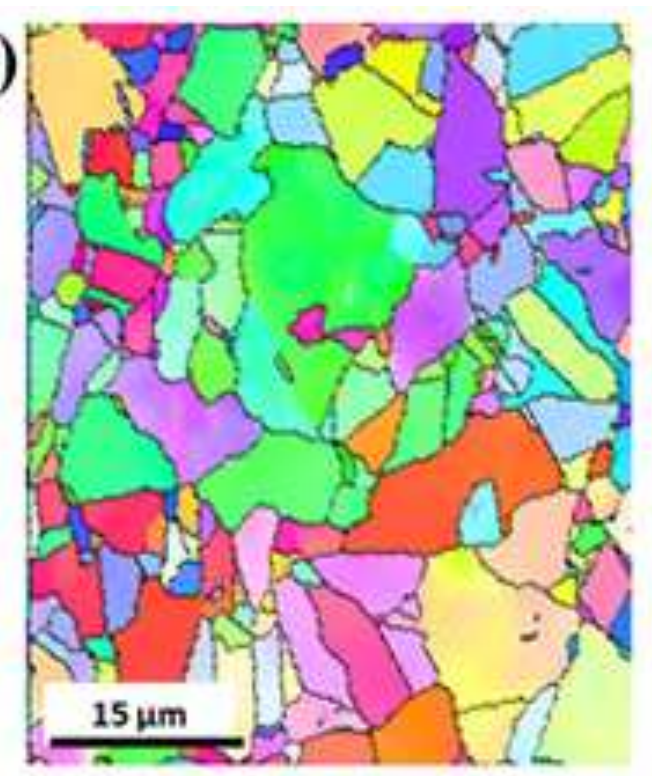

(b)

(c)
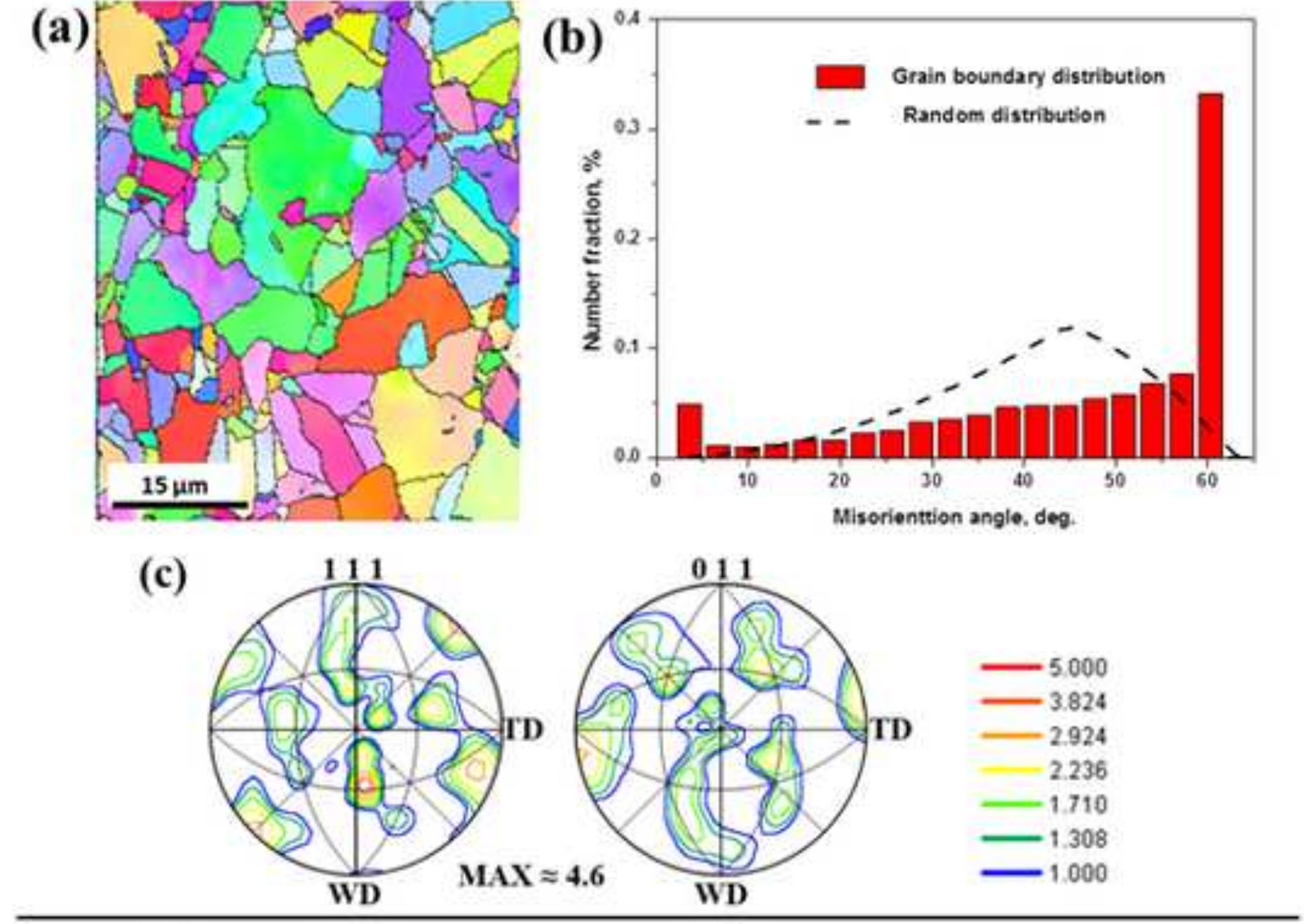

(d)
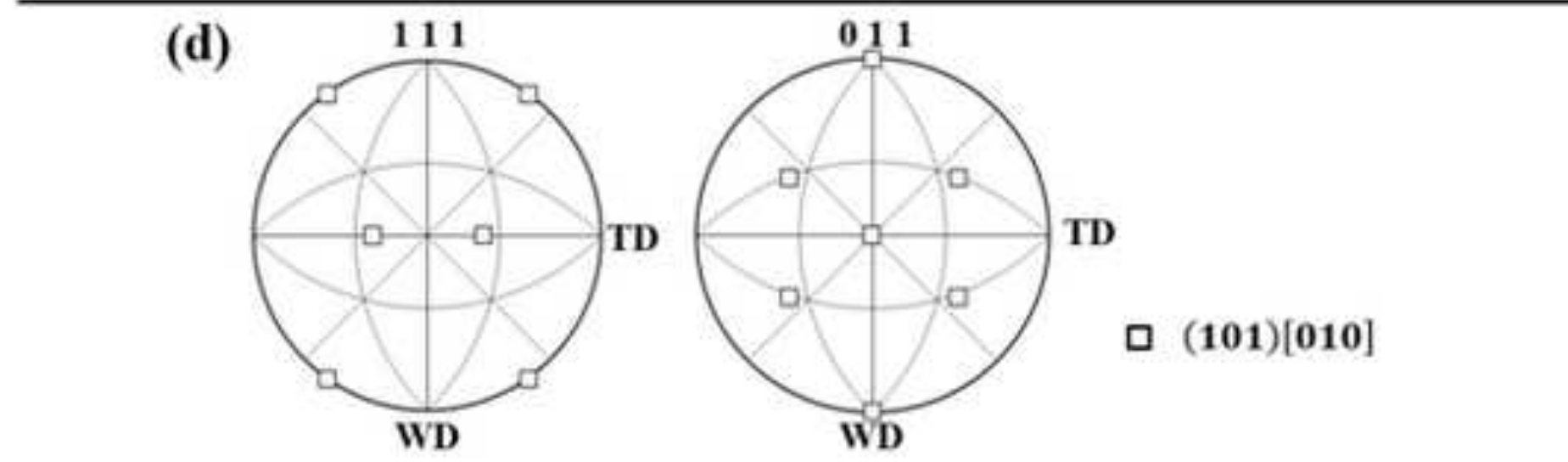

ㅁ (101)[010] 

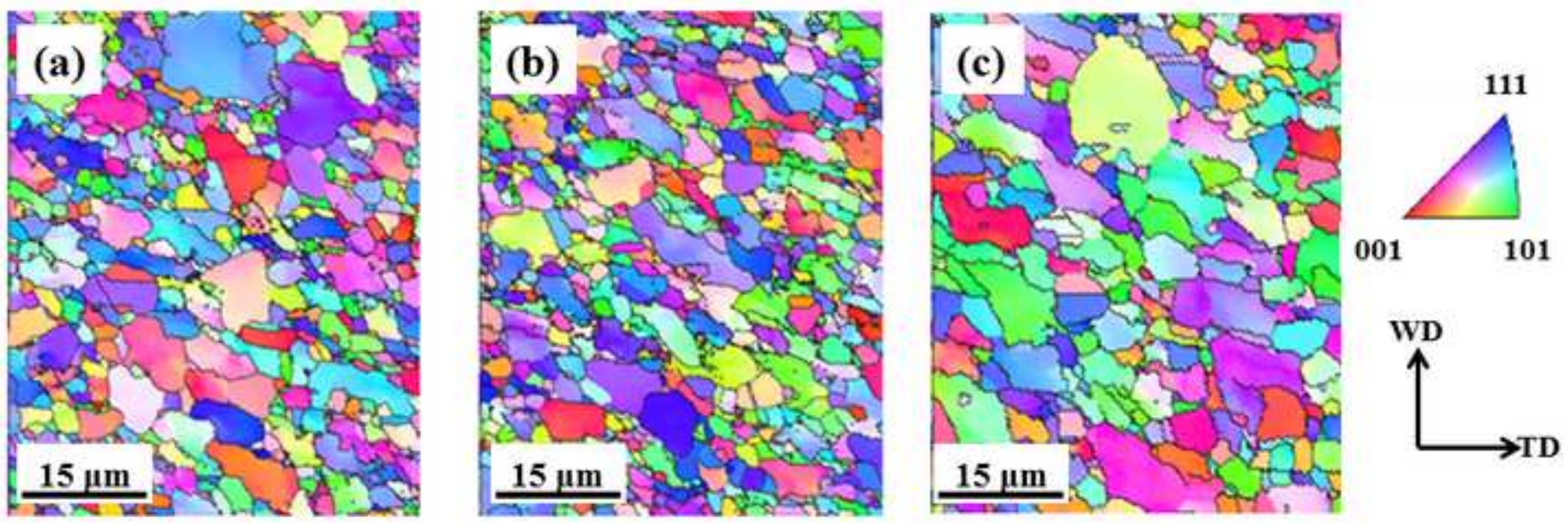

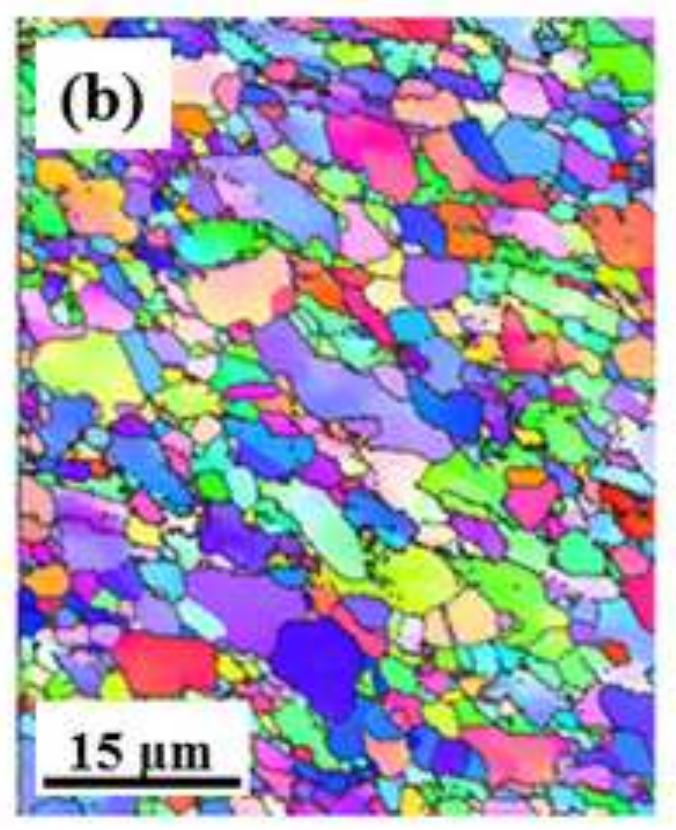

$15 \mu \mathrm{m}$

$15 \mu$ m 


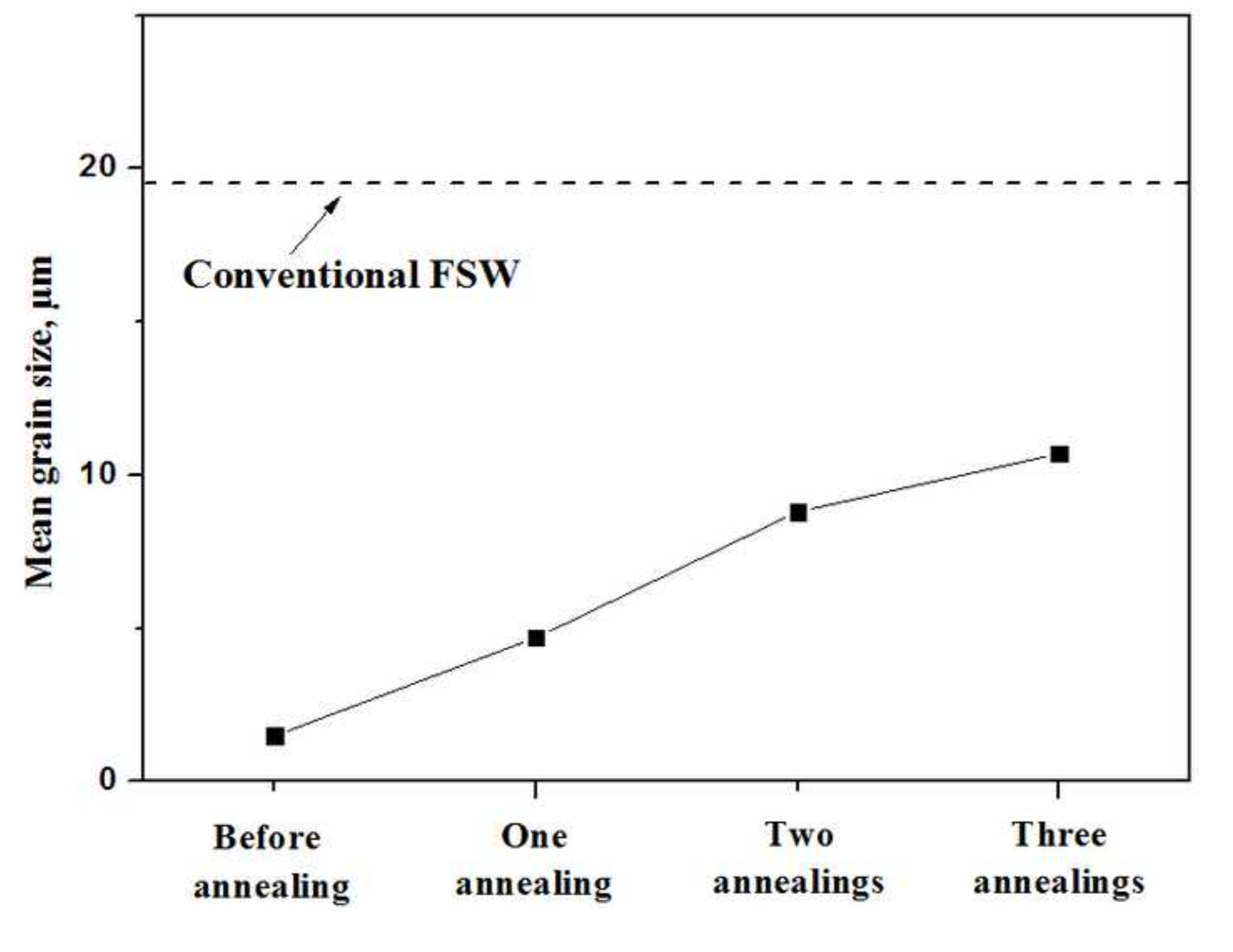
.

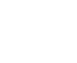

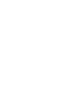
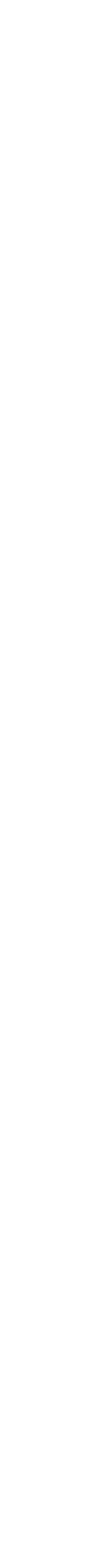


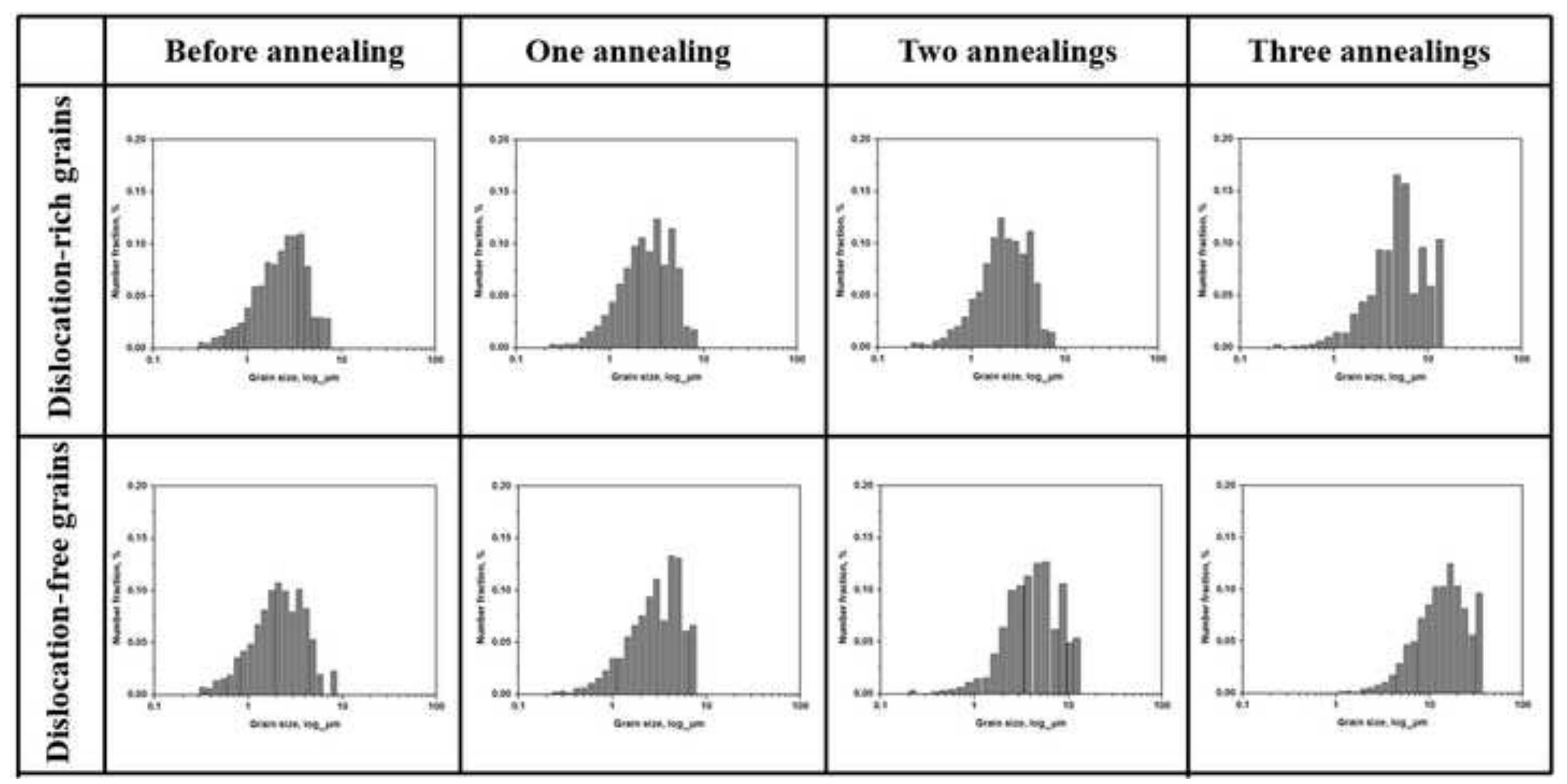



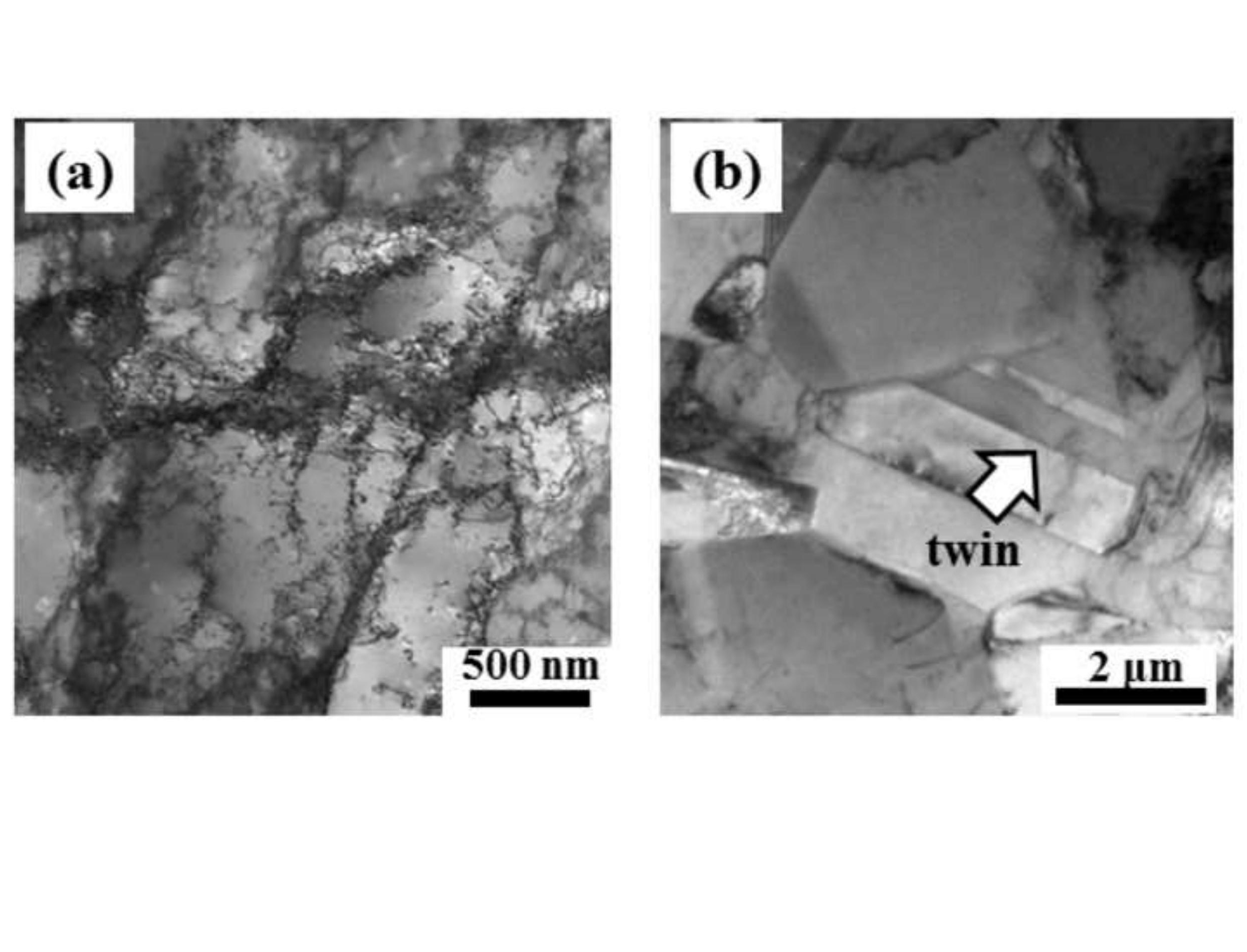

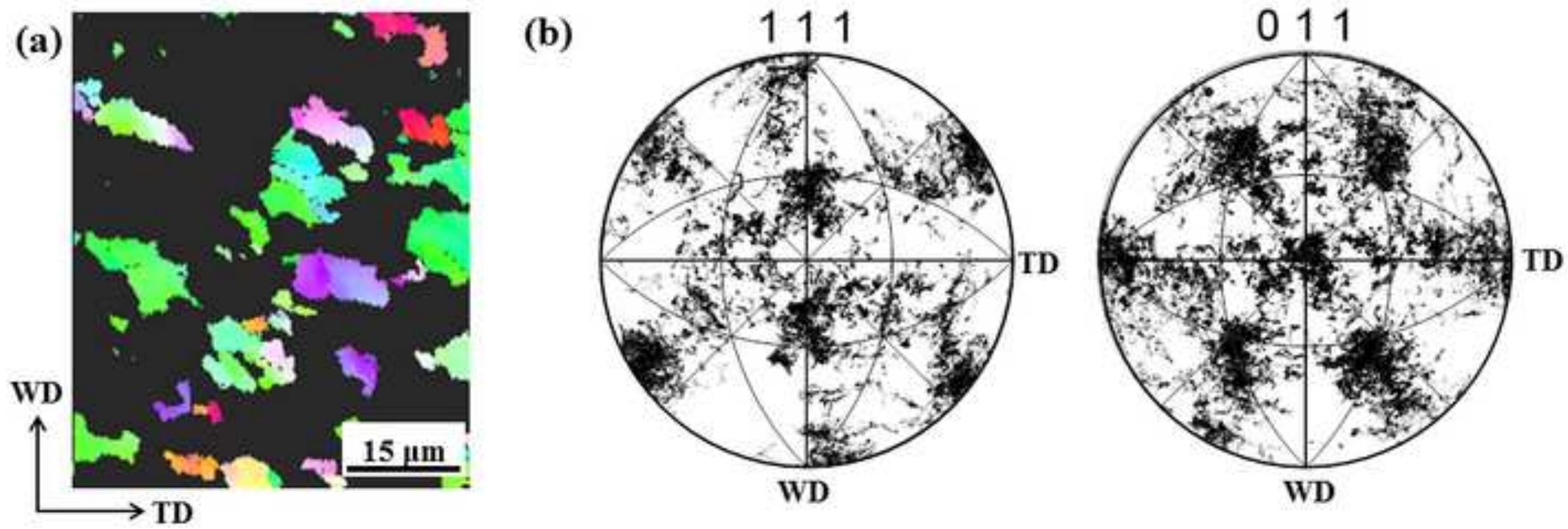


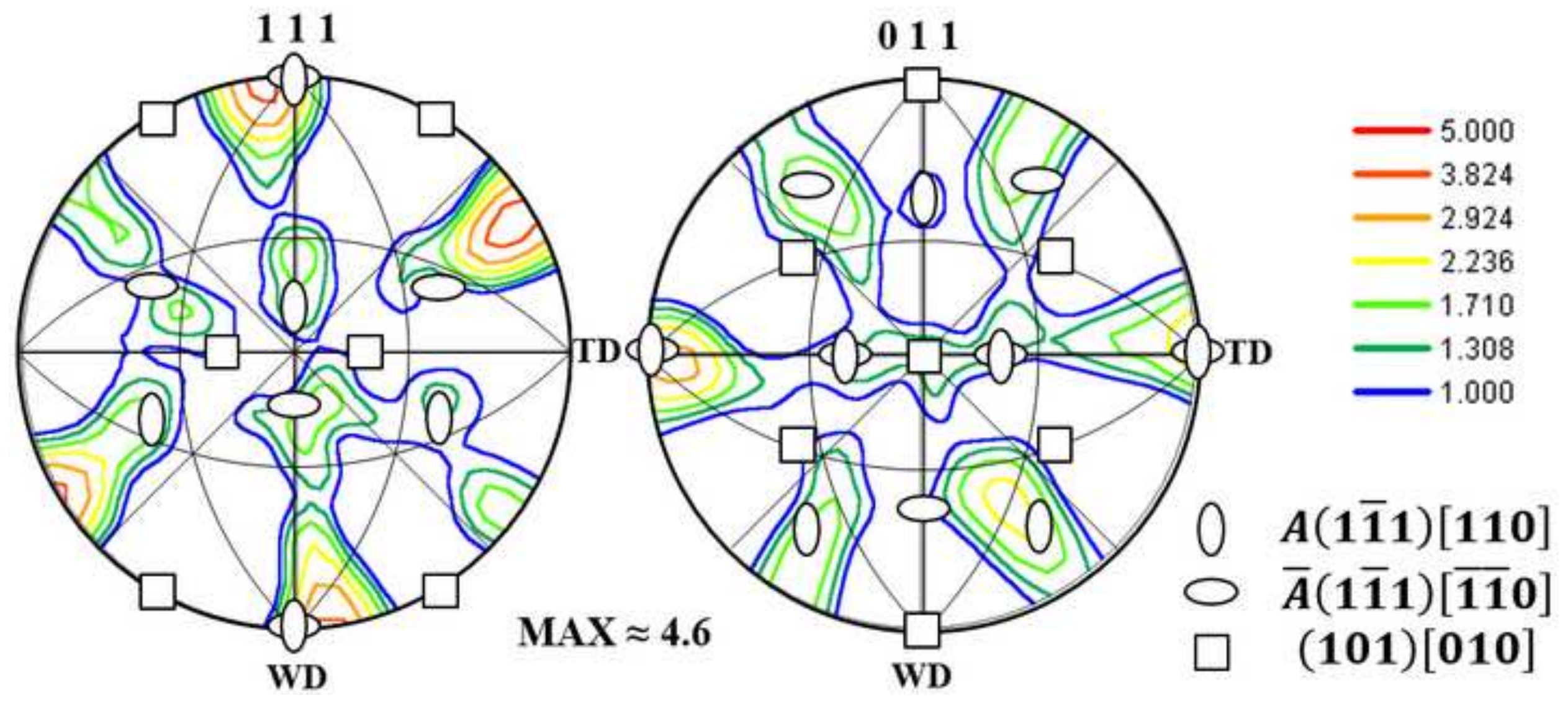

